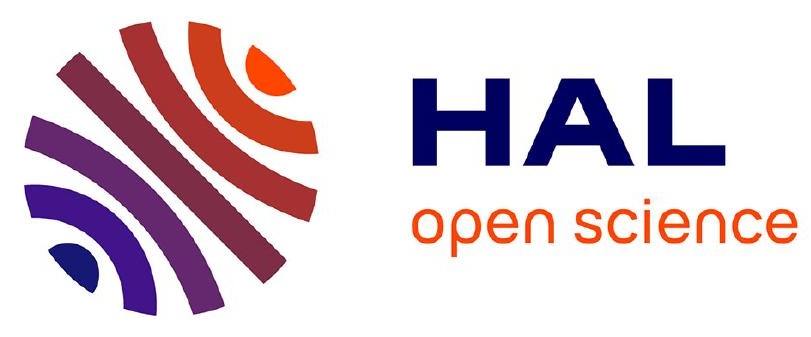

\title{
Rev-Erb modulates retinal visual processing and behavioral responses to light
}

\author{
Ouafa Ait-Hmyed Hakkari, Niyazi Acar, Elise Savier, Perrine Spinnhirny, \\ Mohamed Bennis, Marie-Paule Felder-Schmittbuhl, Jorge Mendoza, David \\ Hicks
}

\section{To cite this version:}

Ouafa Ait-Hmyed Hakkari, Niyazi Acar, Elise Savier, Perrine Spinnhirny, Mohamed Bennis, et al.. Rev-Erb modulates retinal visual processing and behavioral responses to light. FASEB Journal, 2016, 30 (11), pp.3690 - 3701. 10.1096/fj.201600414R . hal-01413114

\section{HAL Id: hal-01413114 https://u-bourgogne.hal.science/hal-01413114}

Submitted on 1 Dec 2021

HAL is a multi-disciplinary open access archive for the deposit and dissemination of scientific research documents, whether they are published or not. The documents may come from teaching and research institutions in France or abroad, or from public or private research centers.
L'archive ouverte pluridisciplinaire $\mathbf{H A L}$, est destinée au dépôt et à la diffusion de documents scientifiques de niveau recherche, publiés ou non, émanant des établissements d'enseignement et de recherche français ou étrangers, des laboratoires publics ou privés. 


\title{
REV-ERBa MODULATES RETINAL VISUAL PROCESSING AND BEHAVIOURAL RESPONSES TO LIGHT
}

\author{
Ouafa AIT-HMYED HAKKARI ${ }^{1,2}$, Niyazi ACAR ${ }^{3}$, Elise SAVIER ${ }^{1}$, Perrine \\ SPINNHIRNY ${ }^{1}$, Mohammed BENNIS ${ }^{2}$ Marie Paule FELDER-SCHMITTBUHL ${ }^{1}$, \\ Jorge MENDOZA ${ }^{1}$ and David HICKS ${ }^{1^{*}}$ \\ ${ }^{1}$ Department of Neurobiology of Rhythms, \\ CNRS UPR 3212, Institut des Neurosciences Cellulaires et Intégratives, \\ 5 rue Blaise Pascal, \\ 67084 Strasbourg France \\ 2 Université Cadi Ayad, Département de Biologie, \\ Laboratoire de Pharmacologie, Neurobiologie et Comportement, \\ Marrakech, Morocco \\ ${ }^{3}$ CNRS UMR6265, Centre des Sciences du Goût et de l'Alimentation, Dijon, France; \\ INRA UMR1324, Centre des Sciences du Goût et de l'Alimentation, Dijon, France; \\ Université de Bourgogne, Centre des Sciences du Goût et de l'Alimentation, Dijon, \\ France \\ * Corresponding Author: David Hicks, address as above (1). \\ Tel: (33) 388456723 \\ FAX: (33) 388456654 \\ e-mail: photoreceptor67@hotmail.com
}

Running Title: Rev-Erba modulates light sensitivity

Funding Sources: The authors are very grateful for generous financial assistance from Retina France (OAH, DH). 


\section{Abbreviations}

CRX, cone-rod homeobox

ERG, electroretinogram

GCL, ganglion cell layer

INL, inner nuclear layer

IPL, inner plexiform layer

ipRGC, intrinsically photosensitive retinal ganglion cell

LD, light-dark cycle

NR2E3, nuclear receptor subfamily 2 , group $\mathrm{E}$, member 3

NRL, Neural Retina Leucine zipper

ONL, outer nuclear layer

OPL, outer plexiform layer

Opn4, melanopsin gene

Rev-erba (NR1D1), nuclear receptor subfamily 1, group D, member 1

SCN, suprachiasmatic nucleus

SLO, scanning laser ophthalmoscopy

ZT, zeitgeber time 


\section{Abstract}

The circadian clock is thought to adjust retinal sensitivity to ambient light levels, yet the involvement of specific clock genes is poorly understood. We explored the potential role of the nuclear receptor REV-ERBa in this respect. In light-evoked behavioural tests, compared to wild-type littermates Rev-Erba ${ }^{-/-}$mice showed enhanced negative masking at low light levels (0.1 lux). Rev-Erba ${ }^{-1-}$ mice retinas displayed significantly higher numbers (62\% more compared to wild-type) of intrinsically photosensitive retinal ganglion cells (ipRGCs), and more intense melanopsin immunostaining of individual ipRGC cells. In agreement with a pivotal role for melanopsin, negative masking at low light intensities was abolished in Rev$E_{r b a}{ }^{--} O p n 4^{-/-}$double null mice. Rev-Erba ${ }^{-/}$mice showed shortened latencies of both "a" and "b" electroretinogram waves, modified scotopic and photopic b-wave and scotopic threshold responses, and increased pupillary constriction, all suggestive of increased light sensitivity. However, wild-type and Rev-Erba ${ }^{-1-}$ mice displayed no detectable differences by in vivo fundus imaging, retinal histology or expression of cell type-specific markers for major retinal cell populations. We conclude that REVERBa plays a major role in retinal information processing, and we speculate that REV-ERBa and melanopsin set sensitivity levels of the rod-mediated ipRGC pathway to coordinate activity with ambient light.

Keywords: circadian clock; photoreceptors; intrinsic photosensitive retinal ganglion cells; negative masking; electroretinogram. 


\section{Introduction}

Many physiological processes within the retina exhibit regular daily variations, such as melatonin synthesis [1], ion channel sensitivity [2], rod-cone coupling [3] and photoreceptor disk shedding [4]. These cyclical activities are thought to adapt retinal sensitivity to the alternating day-night cycle, and to be modulated by both light and circadian clock mechanisms [5]. The retina also coordinates rhythmic behaviour elsewhere in the body, through providing visual input to the central circadian clock in the suprachiasmatic nuclei $(\mathrm{SCN})$ within the ventral hypothalamus. This "non-image forming" vision is mediated by intrinsically photosensitive retinal ganglion cells (ipRGC) $[6,7]$, which project to multiple brain targets including the SCN $[8,9]$. Nonimage forming vision underlies processes such as pupillary constriction, light-dark cycle alignment and negative masking (acute suppression of locomotor activity in response to light) [10-12].

Molecular organisation of the circadian clock has been studied extensively in mammals, especially in the SCN [13], and is based on the interconnection of transcriptiona/translational feedback loops principally involving the core clock genes Clock and Bmal1, with Per1-3 and Cry1-2 forming a negative feedback loop, and Rev-Erba and Ror $\beta$ that act as a further modulatory loop [14]. The coordinated action of this network drives the expression of clock-controlled genes in order to generate rhythmic physiology. Outside of the SCN, clock genes have been identified in almost all cell types including the retina $[5,15]$, and form a robust oscillating network driving retinal physiology [16], but experimental proof of the involvement of specific clock genes in a given retinal behaviour is not common. Available evidence suggests an important role for Rev-Erba in the retina: we showed that the protein product of RevErba complexes with the rod-specific transcription factors NRL, CRX and NR2E3, 
leading to additive stimulation of rhodopsin transcription [17]. More recently, it was shown that siRNA silencing of Rev-Erba mRNA within the developing eye leads to pan-retinal spotting and reduced amplitude of the electroretinogram (ERG) "b" wave [18], and that Rev-Erba expression counteracts loss of rod-specific transcription factor Nr2e3 and prevents degeneration [19]. But clear links between Rev-Erba gene expression, visual processing and behavioural responses have not yet been established.

We have used a variety of anatomical, cellular and molecular biological, functional and behavioural approaches to explore the retinal phenotype of mice lacking the Rev-Erba gene. The data show that Rev-Erba ${ }^{-/-}$mice display a unique and remarkable increased sensitivity to light with enhanced outer and inner retinal responses, and higher ipRGC numbers, giving rise to modified light-mediated behaviours. The data suggest that Rev-Erba is important in setting rod pathway sensitivity levels.

\section{Materials \& Methods}

\section{Animals}

Experiments were conducted using homozygote knockout mice in which the normal Rev-Erba gene was disrupted by replacing exons 3 and 4 (encoding the DNA binding domain of REV-ERBa) and part of exons 2 and 5 by an in-frame LacZ allele and a PGK-neo gene using homologous recombination in SV129 ES cells [20] (generous gift of Dr. U. Schibler, Dept. Molecular Biol., Univ. Geneva, Switzerland). We also generated double knockout $R e v-E r b \alpha^{-/-} O p n 4^{-/-}$by crossing with melanopsin null mice in which a loss-of-function mutation was created through deletion of amino acids 116 to 128 [21] (generous gift of Dr. P. Bourgin, INCl Strasbourg). Mice were bred as 
heterozygotes (Rev-Erbo $\left.{ }^{+/}\right)$in our animal facilities (Chronobiotron, UMS3415, Strasbourg), and maintained on an LD cycle [12L/12D, 300 lux broad spectrum white light during the light phase, dim red light ( $<5$ lux) during the dark phase], with an ambient temperature of $22 \pm 1^{\circ} \mathrm{C}$. The animals were supplied ad libitum with water and standard chow. Genotyping of littermates allowed selection of Rev-Erba ${ }^{+/+}$

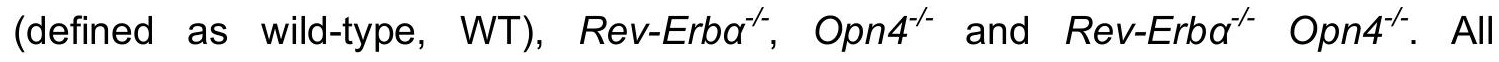
experimental procedures were performed in accordance with the rules laid down by the European Communities Council Directive of 24 November 1986 (86/609/EEC), the Association for Research in Vision and Ophthalmology Statement on Use of Animals in Ophthalmic and Vision Research, as well as institutional ethical guidelines.

\section{Behavioural experiments}

Nocturnal rodents exhibit strong inhibition of locomotor activity by light (negative masking), dependent on light intensity [22]. We evaluated the negative masking responses at different light intensities in two different experiments: in the first we used WT and Rev-Erba ${ }^{-/}$animals ( $n=6$ per genotype); in a second experiment we used WT (n=4), Rev-Erba ${ }^{-/}(n=4), O p n 4^{--}(n=5)$ and Rev-Erba ${ }^{-/} O p n 4^{-/}(n=5)$ mice. Animals were housed in individual cages under a LD cycle (12/12; during the dark period animals were in total darkness). Locomotor activity was monitored with infrared detectors on top of the cage, linked to an automated recording system (CAMS, Circadian activity monitoring system, Lyon, France). Data were recorded every 5 min. Clocklab software (Actimetrics, Wilmette, IL) was used to plot locomotor activities as actograms and to determine the total activity of each animal. Mice were exposed to $3 \mathrm{~h}$ of light stimulation, from ZT14 ( $2 \mathrm{~h}$ after lights off) to ZT17, at intensities of $0.1,22$ or 100 lux given on subsequent, alternate nights (ie. each $3 \mathrm{~h}$ 
light exposure was separated by a normal $24 \mathrm{~h}$ LD cycle without light pulse during the dark period), as follows: d 1: normal LD; d 2: ZT14-17 0.1 lux; d 3: normal LD; d 4: ZT14-17 22 lux; d 5: normal LD; d 6: ZT14-17 100 lux; d 7: normal LD. We evaluated the percent of activity change during light exposure relative to the activity during the same period (from ZT14 to ZT17) in the normal LD cycle the day before stimulation (d1).

\section{Retinal Wholemount Immunohistochemistry}

We also performed immunolabelling of retinal wholemounts prepared from 3-6 month WT and Rev-Erba ${ }^{-/}$mice using polyclonal anti-melanopsin (Opn4) antibody (AF006, generous gift of Dr. I. Provencio, Univ. Charlottesville, N.C., USA) ( $n=5$ animals for each strain), as previously published [23, 24]. Retinas were incubated in antibody for $48-72 \mathrm{~h}$ at $4^{\circ} \mathrm{C}$ under gentle agitation, washed extensively in PBS and incubated overnight in goat-anti rabbit IgG-Alexa 488 (Molecular Probes Inc., Eugene OR, USA). Quantification was performed by counting total numbers of immunolabelled cells within the GCL under $x 40$ optics. Sections and whole-mounted retinas were observed using either a Nikon Optiphot 2 fluorescence microscope (Nikon, Melville, NY, USA) equipped with differential interference contrast optics, and images were captured using Nikon NIS-Elements BR 3.0 image analysis software (Nikon, Melville, NY USA). Photographs were taken with identical exposure times between control and treated specimens. Any Photoshop ${ }^{\mathrm{TM}}$ treatment of images was done using identical parameters between the two sets. These treatments were performed on whole images and did not obscure or misrepresent information present in the original data. Cholera B tracing of axonal projections

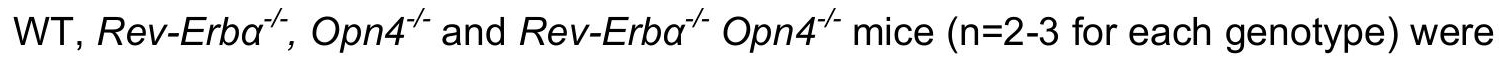
anesthetized with ketamine $®(87 \mathrm{mg} / \mathrm{kg}$, i.m. $)$ and xylazine ${ }^{\circledR}(1.3 \mathrm{mg} / \mathrm{kg}$, i.p.) prior to 
unilateral intravitreal injection of $1 \mu \mathrm{l}$ cholera toxin B (CTB) subunit-Alexa 555 (Life Technologies Invitrogen) into the left eye, as described in [25]. Animals were maintained under LD cycle (12/12, intensity 100 lux), and $48 \mathrm{~h}$ after CTB injection the animals were killed at ZT7 by pentobarbital overdose and immediately perfused with $50 \mathrm{ml} \mathrm{4 \%}$ paraformaldehyde in PBS. After perfusion, the brains were dissected free of the skull and post-fixed overnight at $4^{\circ} \mathrm{C}$. The superior colliculi were removed by undercutting with sharp forceps under dissecting microscope guidance, and examined by fluorescence optics to ensure complete filling of the right hemisphere as a control for successful intravitreal injection. After cryoprotection of the remaining brain tissue in 10, 20 and $30 \%$ sucrose, $30 \mu \mathrm{m}$ coronal sections were obtained by cryostat, using the Brain Atlas as reference for the SCN, and free floating sections were collected and mounted in series on microscope slides. Sections were viewed with 40x objectives using a Nikon Optiphot 2 microscope equipped with filters, and photographs were taken covering the entire SCN. The surface area occupied by fluorescently tagged CTB was quantified using Image $J^{\mathrm{TM}}$ software (NIH, USA).

\section{Electroretinography}

Electroretinograms (ERG) were recorded as described in previously published procedures [26, 27]. The recording setup featured a Ganzfeld bowl, an amplifier, and a computer-based control and recording unit (RETI port/scan 21, Stasche \& Finger $\mathrm{GmbH}$, Roland Consult, Brandenburg, Germany). WT (n=6) and Rev-Erba ${ }^{-/-}(\mathrm{n}=6)$ mice were anesthetized by sub-cutaneous injection of ketamine $(50 \mathrm{mg} / \mathrm{kg}$, Imalgène $\AA$ 1000, Merial, Lyon, France) and xylazine (10 mg/kg, Rompun $® 2 \%$, Bayer, Puteau, France). The pupils were dilated with $0.5 \%$ tropicamide (Ciba Vision Ophthalmics, Blagnac, France). After 5 min, animals were positioned on a warming plate to maintain a constant body temperature, and ground, reference and corneal 
electrodes (thin gold wire with a $2 \mathrm{~mm}$ ring end) were placed accordingly. Methylcellulose (Humigel; Virbac) was applied to ensure good electrical contact and to keep the cornea hydrated during the entire procedure. Single-flash recordings were obtained under both dark-adapted (scotopic) and light-adapted (photopic) conditions, from both eyes simultaneously after the mice were placed in the Ganzfeld bowl. Light-adaptation was performed with a background illumination of $30 \mathrm{cds} / \mathrm{m} 2$ presented 10 minutes before recording to stabilize photopic responses. Single flash stimuli were presented with increasing intensities, from $3 \times 10^{-4}$ to $10 \mathrm{mcds} / \mathrm{m}^{2}$, divided into ten steps: $3 \times 10^{-4}, 10^{-3}, 3 \times 10^{-3}, 10^{-2}, 3 \times 10^{-2}, 10^{-1}, 3 \times 10^{-1}, 1,3$, and $10 \mathrm{mcds} / \mathrm{m}^{2}$ ). Recordings were obtained in the morning and early afternoons, and genotypes were randomized to avoid bias from circadian variations in responses.

Scotopic Threshold Responses (STRs) were recorded independently following overnight dark adaptation of a separate group of WT $(n=7)$ and $\operatorname{Rev}-\operatorname{Erba}^{-/-}(\mathrm{n}=6)$ mice, using the same procedures and with intensities of $3 \times 10^{-5}, 6 \times 10^{-5}$, and $9 \times 10^{-5}$ $\mathrm{mcds} / \mathrm{m}^{2}$, essentially as described in [28]. These very faint flash stimuli were obtained by placing neutral density filters over the LED display within the Ganzfeld. For each intensity, 25 responses were averaged with an inter-stimulus interval of 7 seconds.

\section{Pupillometry}

Following dark-adaptation of at least 8 hours, animals were anesthetized by subcutaneous injection of ketamine $\left(50 \mathrm{mg} / \mathrm{kg}\right.$, Imalgène ${ }^{\circledR} 1000$, Merial, Lyon, France) and xylazine (10 mg/kg, Rompun ${ }^{\circledR} 2 \%$, Bayer, Puteau, France) in a completely dark room under $\operatorname{dim}$ red light $(650 \mathrm{~nm})$. As according to published procedures for analysing the pupillary light reflex (PLR) [29], they were then placed in another room under very dim light (intensity 1-2 lux) in front of the camera of the Heidelberg Retina Angiograph (HRA I, Heidelberg Engineering, Germany), set to the 
$830 \mathrm{~nm}$-infrared laser. A single white flash was delivered to the eye (flash taken from a disposable camera, model Kodak Fun Saver, Kodak, Chalon sur Saône, France), 5 s after the start of HRA video recording. The absolute pupil diameter was measured every second before flash, every 500 ms during $15 \mathrm{~s}$ after light stimulus, and then every second for $5 \mathrm{~s}$ using the embedded software of the HRA. The baseline pupil diameter was determined from the mean pupil size during the $5 \mathrm{~s}$ preceding the light stimulus. All pupil sizes were converted to relative pupil diameter against the baseline $(=100 \%)$.

\section{Histological Analysis}

Following functional or behavioural testing, animals were killed by $\mathrm{CO}_{2}$ inhalation and decapitation. Eyes were treated exactly as described in previous publications [27, 30]. Cell layer thicknesses and nuclear density counts were performed according to previously published standardized methodologies [30, 31]. Micrographs were captured from the posterior eyecup within $1 \mathrm{~mm}$ of the optic nerve head. A rectangle covering $200 \mu \mathrm{m}$ in width, extending over the entire retinal width from the photoreceptor outer segments (OS) to the inner limiting membrane was placed over the image, and widths of the outer nuclear layer (ONL), inner nuclear layer (INL) and ganglion cell layer (GCL), as well as the outer and inner plexiform layers (OPL and

IPL respectively) were recorded. Numbers of cell nuclei for each layer within the boundaries of the rectangle were counted manually. This operation was repeated for a minimum of five images for each eye from three different animals of each strain.

\section{Retinal Immunohistochemistry}

Immunohistochemical staining was performed exactly as described previously [23, $27,30]$. Sections were incubated overnight at $4^{\circ} \mathrm{C}$ with monoclonal anti-rhodopsin rho-4D2 [32]. This antibody has been used widely and its specificity has been verified 
by appropriate immunological controls. Secondary antibody incubation was performed at room temperature for $2 \mathrm{~h}$ with goat anti-mouse IgG-Alexa 488 conjugated antibody (Molecular Probes Inc., Eugene, OR, USA). Cell nuclei were stained with 4,6-di-amino-phenylindolamine (DAPI) (Molecular Probes Inc.). Immunolabelling studies were performed a minimum of three times for each antibody, using at least four sections obtained from different individuals. All experiments gave similar results, and representative stained images are shown.

\section{Western Blotting}

Retinas ( $n=3-4$ animals were dissected from adult (3-6 months) mice of both strains, immediately frozen in liquid nitrogen and stored at $-80^{\circ} \mathrm{C}$. Tissue extraction, migration on polyacrylamide gels and immunoblotting were done as described previously [27, 30]. The membranes were incubated in rho-4D2 $(0.05 \mu \mathrm{g} / \mathrm{ml})$, incubated overnight at $4^{\circ} \mathrm{C}$, then incubated with goat anti-mouse IgG-horseradish peroxidase secondary antibodies (1:20,000; Jackson ImmunoResearch Laboratories, West Grove, PA). Immunoreactive bands were visualized using the Super Signal chemiluminescence ECL kit (Super Signal West Pico; Pierce, Rockford, IL) according to the manufacturer's instructions. Analyses of immunoblots were performed for three retinas from each strain, and normalised against anti- $\beta$-actin immunoblots of the same membrane after stripping.

mRNA extraction and Quantitative Real-Time PCR

WT $(n=3)$ and Rev-Erba ${ }^{-/}(n=5)$ animals housed in LD 12:12 were euthanized at ZT17. Whole retinas were rapidly collected and immediately frozen on dry ice and stored at $-80^{\circ} \mathrm{C}$. Total RNAs were extracted with TriReagent (MRC, Cincinnati, USA) and purified with the RNeasy Micro Kit (Qiagen Gmbh, Hilden, Germany) according to the manufacturer's instructions. Total RNA quantity and purity $\left(A_{260} / A_{280}\right.$ and 
$A_{260} / A_{230}$ ratios between 1.8-2) were measured using a NanoDrop ND-1000 V 3.5 Spectrophotometer (NanoDrop Technologies, USA) and the RINs (higher than 7) were assessed using the 2100 Bioanalyzer (Agilent Technologies, Santa Clara, CA, USA). 500ng of total RNA were reverse transcribed into first-strand cDNA using the High-capacity-RNA-to-cDNA kit (Applied Biosystems, Foster City, USA). Quantitative Real-time PCR was performed using an Applied Biosystems 7300 Real-time PCR System and $1 \mu \mathrm{L}$ of cDNA, 1X TaqMan Gene Expression Assay (Applied Biosystems) and 1X TaqMan Gene Expression Master Mix (Applied Biosystems). The following TaqMan Gene Expression Assays were used: Opn4 (Mm00443524_m1), Tbp (Mm00446971_m1), Hprt (Mm01545399_m1) and GAPDH (Mm99999915_g1). The PCR program was: $10 \mathrm{~min}$ at $95^{\circ} \mathrm{C}$, followed by 40 cycles of denaturation at $95{ }^{\circ} \mathrm{C}$ for $15 \mathrm{~s}$ and annealing-elongation at $60{ }^{\circ} \mathrm{C}$ for $1 \mathrm{~min}$. Each PCR reaction was done in duplicate. A dilution curve of the pool of all CDNA samples was used to calculate the amplification efficiency for each assay. qPCR data was analyzed using the $\Delta \mathrm{Cq}$ method modified to take into account gene-specific amplification efficiencies and multiple reference genes (qBase v1.3.5) [33]. Opn4 transcript levels were normalized to Tbp, Hprt, and GAPDH and calculated relative to the sample showing the lowest expression, which was rescaled to 1 .

\section{Statistics}

Results are expressed as means \pm S.E.M. (or means \pm S.D. for $\mathrm{qPCR}$ data). Comparisons of two groups were performed by using t-test. Comparison of several groups was performed using factorial analysis of variance (ANOVA) for independent and repeated measures, followed by a post hoc LSD test of Fisher. $P<0.05$ was considered as statistically significant. Calculations were performed using 
STATISTICA 8.0 (StatSoft, France) or SigmaPlot 12 software (Systat Software, San Jose, CA, USA).

\section{Results}

Light-mediated behaviours in Rev-Erba ${ }^{-/}$mice show increased light sensitivity compared to WT mice

Rev-Erba ${ }^{+/+}$(wild-type, WT) and Rev-Erba ${ }^{-/}$littermate mice were subjected to a $3 \mathrm{~h}$ light pulse during the early night (zeitgeber time, ZT14-17) of standard light/dark (LD) cycles, using successive light intensities of 100, 22 and 0.1 lux, each separated by a normal LD cycle with full dark period (Figure 1A). In WT mice, whereas both 100 and 22 lux pulses induced significant negative masking responses (54\% reduction at 100 lux and $25 \%$ reduction at 22 lux in the activity levels observed under normal dark conditions at the corresponding time window on the preceding night), there was no negative masking behaviour following a 0.1 lux pulse. On the other hand, Rev-Erba ${ }^{-1-}$ mice displayed significant negative masking behaviour to all three light intensity regimens: 100 lux (61\% reduction), 22 lux (39\% reduction) and 0.1 lux (38\% reduction) in motor activity compared to the same time period under normal dark conditions (Figure 1B) (genotype effect: $F_{1,30}=7.75, P=0.009$ ), with a light effect $(F$ $2,30=8.99, P=0.0008)\left(\right.$ genotype $X$ light intensity effect: $\left.F_{2,30}=5.06, P=0.013\right)$. This result was confirmed by using a combined jet-lag and stepped light intensity protocol in which $\mathrm{KO}$ mice mostly showed a strong masking response subsequent to a shift to a new LD cycle, compared to WT animals (Figure S1).

Light hypersensitivity induced by Rev-Erba gene deletion depends on melanopsin

Since this enhanced photic response could be due to differences in ipRGC number and/or melanopsin expression, we examined these parameters in the two strains. 
Melanopsin immunoreactivity was clearly more intense in Rev-Erbo ${ }^{-/-}$mice, with pronounced staining of cell bodies and dendritic arborisations compared to WT using the same fluorescent exposure times (Figure 2A). Quantification of the total number of immunolabelled ipRGC cell bodies within whole flat-mounted retinas demonstrated a $62 \%$ increase in Rev-Erba ${ }^{-/}$mice compared to WT [Figure 2B; $F_{1,8}=11.484, P=$ 0.01 (Anova, one variable); $\mathrm{t}=-3.389, \mathrm{P}=0.010$ ( $\mathrm{t}$ Test)]. We further separated total ipRGCs into the two major sub-populations, M1 and M2, identified by the stronger melanopsin immunoreactivity and different position of the soma in M1. M1 ipRGC showed a $\sim 75 \%$ increase in Rev-Erba ${ }^{-/}$compared to WT mice (Figure 2C; $F_{1,4}=$ $36.55, P=0.0037))$. By inference based on the percentages of M1 and M2 ipRGCs in mouse retinas [ $44 \% \mathrm{M} 1,50 \% \mathrm{M} 2: 26$ ], M2 ipRGC showed a roughly $50 \%$ increase in mutant retinas.

Since these immunohistochemical data strongly implicated ipRGC in the enhanced behavioural responses to light, we repeated the negative masking

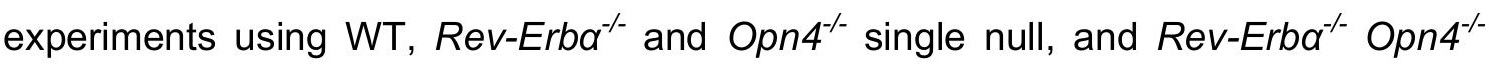
double null mice. As before, we applied stepped $3 \mathrm{~h}$ light pulses of 100, 22 and 0.1 lux intensity during the early night. At 0.1 lux, only Rev-Erbar- mice showed significant light-induced inhibition, the other three strains all possessing normal activity (Figure 2C; $F_{3,17}=3.91, P=0.03$ ). Negative masking was immediately evident in Rev-Erba ${ }^{-/}$mice, with rapid diminution of general activity compared to littermates from the other genotypes (Figure 2D). As before, 100 and 22 lux pulses revealed negative masking responses in WT and Rev-Erba/- mice, whereas Opn4 $4^{-1-}$ mice did not show significant inhibition over the $3 \mathrm{~h}$ period (Figure S2A). 
Cholera toxin tracing of ipRGC axonal projections to the SCN showed robust innervation in all four genotypes, with label filling the ventral regions of the nuclei as well as being present within the optic chiasma (Figure S2B).

Rev-Erba ${ }^{--}$mice show increased pupillary light reflexes (PLR) compared to WT mice The basal level of pupillary constriction appeared greater in Rev-Erba ${ }^{-/-}$compared to WT mice, but this was not statistically significant $(p=0.10$, Figures $3 A$ and $B)$. Light flash stimulation resulted in rapid pupillary constriction that was followed by progressive return towards baseline in both genotypes (Figures $3 \mathrm{~A}$ and $\mathrm{C}$ ). The maximal constriction amplitude was larger for Rev-Erba ${ }^{-/-}$mice (mean value $24 \%$ ) compared to WT controls (mean value 14\%) under our experimental conditions (Figure 3C). The similar shapes of the PLR curves between 5 and $20 \mathrm{~s}$ after stimulation indicate rapid dilation of the pupil after maximal constriction, comparable between WT and Rev-Erbo'-/ mice.

Rev-Erba ${ }^{-/-}$mice show altered retinal light flash responses compared to WT mice In order to see whether modifications in the light information pathway were present upstream of the ipRGC in mutant mice, functional analyses of Rev-Erba ${ }^{-/-}$and WT mice were performed by recording of STR, scotopic and photopic ERG patterns. WT STR traces showed a conventional profile of a large positive STR (pSTR) followed by a rapid hyper-polarisation and negative STR (nSTR). On the other hand, Rev-Erba ${ }^{-/}$ STR were characterized by a distinctive hump on the descending part of the response (Figure 3D), whose size was not related to the stimulus intensity. The presence of this distortion meant that it was not possible to quantify the amplitude of the nSTR in mutant mice. When compared to controls, Rev-Erba ${ }^{-/-}$mice displayed a significantly higher pSTR, but only at a stimulus intensity of $3 \times 10^{-5} \mathrm{mcds} / \mathrm{m}^{2}$ 
$(\log$ (intensity) $=-4.60$, Figure 3E). No difference between groups was observed in pSTR latencies (data not shown).

Compared to WT, Rev-Erba ${ }^{-/}$mice displayed atypical dark-adapted scotopic ERG responses (Figure 4A, left panel). The most visible difference consisted in the response of inner retinal cells, and as seen for the STR was characterized by the presence of a single or double hump on the descending part of the b-wave at all intensities of stimulation (Figure 4A). This distortion was not due to changes in the pattern of oscillatory potentials (data not shown). When superimposed on that of WT mice, Rev-Erba ${ }^{-/-}$mice also displayed reduced implicit times for both the a- and bwaves of the ERG (Figure 4A). The shortened latencies were observed in all Rev$\mathrm{Erba}^{-/}$animals irrespective of the size of the hump on the descending part of the bwave. Measurement of ERG a- and b-wave latencies at different intensities of scotopic stimulation confirmed a significant reduction in Rev-Erba ${ }^{-/-}$mice $\left[F_{1,45}=6.76\right.$, $P=0.048$ for $b$-wave (Figure 4B); $F_{1,35}=11.332, P=0.02$ for a-wave Figure $4 \mathrm{D}$ )], and is shown in higher detail in a representative single recording in Figure 4C. Amplitude of the b-wave showed a tendency to be higher in Rev-Erba ${ }^{-/-}$mice than in WT, in particular at stimulus intensities corresponding to rod-evoked responses (from 0.3-100 mcds $\left./ \mathrm{m}^{2}\right)$, although not reaching statistically significant difference by two-way ANOVA analysis (Figure 4E). No modification or tendency was observed for the scotopic a-wave amplitude in Rev-Erba ${ }^{-/}$mice (Figure 4F).

Light-adapted photopic ERGs recorded from both genotypes also showed the presence of an atypical "humped" b-wave in Rev-Erba ${ }^{-/}$compared to WT mice (Figure 4G).

Rev-Erba ${ }^{-/}$mice do not exhibit detectable retinal structural changes compared to WT mice 
Since our earlier work demonstrated that Rev-Erba is involved in regulation of rhodopsin transcription [17], we also examined general histological structure (Figure $5 \mathrm{~A})$, rhodopsin expression levels and photoreceptor phenotype in Rev-Erba ${ }^{-/}$mice compared to WT littermates. There were no differences in overall retinal structure as determined either by cell density (Figure 5B) [ONL $(F$ 1,4 $=0.615, P=0.477$ ); $\mathrm{t}=0.784 ; \mathrm{p}=0.477, \mathrm{INL}(F 1,4=2.941, P=0.162) ; \mathrm{t}=1.715 ; \mathrm{p}=0.162, \mathrm{GCL}(F 1,4=$ 2.584, $P=0.183)] ; \mathrm{t}=1.607 ; \mathrm{p}=0.183$ ] or thickness of cell layers (Figure $5 \mathrm{C})$ [ONL $(F$ $1,4=0.271, P=0.630) ; \mathrm{t}=0.521 ; \mathrm{p}=0.630, \mathrm{OPL}(F 1,4=0.817, P=0.417) ; \mathrm{t}=-0.904 ;$ $\mathrm{p}=0.417, \mathrm{INL}(F 1,4=0.0566, P=0.824) ; \mathrm{t}=-0.238 ; \mathrm{p}=0.824, \operatorname{IPL}(F 1,4=0.983, P=$ 0.378)] by one-way ANOVA and t test. We performed immunohistochemical staining for rhodopsin and a number of cone- and bipolar cell-specific proteins using frozen retinal sections prepared from the two genotypes: both intensity and distribution of the respective immunostained profiles were similar (Figures $5 \mathrm{D}-\mathrm{H}$ ). We saw no quantitative differences in the level of rhodopsin expression by western blotting of retinal extracts from WT and Rev-Erba ${ }^{-/}$mice (Figure 5I), or of other retinal proteins (mid-wavelength sensitive cone opsin, PKCa or synaptophysin: Figure S3A). Finally, quantification of melanopsin mRNA expression levels by qPCR showed similar values for both genotypes (Figure $5 \mathrm{~J}$ ).

The fundus aspect of anaesthetized living mice was examined by scanning laser ophthalmoscopy. Under different modes of illumination, their retinas appeared normal without visible spots or inclusions, autofluorescent granules or pigmentary patches in either genotype. Retinal blood vessels also exhibited normal aspects and branching patterns and did not differ between the two strains (Figure S3B). 


\section{Discussion}

The present study describes a novel visual phenotype in Rev-Erba ${ }^{-/}$mice, namely a marked hypersensitivity to low ambient light levels, seen at the level of the eye as increased pupillary constriction, accelerated time-to-peak and prolonged atypical bwave ERG and STR patterns, and increased numbers and melanopsin-like immunoreactivity of ipRGC; and at the level of the brain by heightened negative masking responses, compared to normal WT littermate controls. Furthermore, the enhanced negative masking was abolished by cross-breeding the mice onto a melanopsin-null background. These features are very different from the visual phenotype previously attributed to knockdown-of-function Rev-Erba mice [18], and implicate this clock gene in modulating light sensitivity levels and visual information processing.

We first investigated an important aspect of light information processing by the brain, namely light-evoked negative masking of locomotor output. There was clear evidence for heightened behavioural light sensitivity in knockout mice especially at low light levels, manifested as enhanced negative masking. Rev-Erba- mice exposed to very faint light pulses ( 0.1 lux) exhibited significantly reduced activity compared to WT mice exposed to the same intensities. Negative masking is proposed to depend on ipRGC, since melanopsin knockout mice show altered masking responses to light compared to WT animals [12]. The enhanced masking

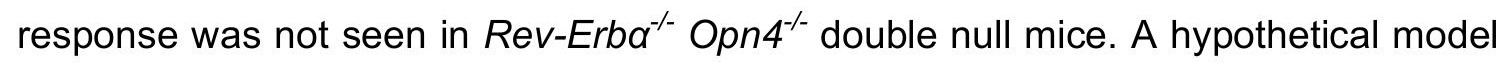
to explain these findings is shown in Figure 6, interpreted as follows: ipRGC output is a summation of intrinsic light stimulation (melanopsin excitation) and synaptic input from rod and cone-specific bipolar cells. In WT mice, under sufficiently high levels of 
ambient light the combination of these influences contributes to membrane depolarisation and triggering of action potentials in ipRGCs. At very low ambient light intensities (ie. 0.1 lux), both sources of input would decline till excitation is no longer possible, although the resting potential of ipRGCs would still be near to threshold levels, as suggested by previous reports [34]. In the Rev-Erba ${ }^{-/-}$mice, increased input from the rod pathway, and/or the increased expression of melanopsin, due to a currently unknown mechanism, would be sufficient to depolarise ipRGCs even at low light levels. In the Rev-Erba ${ }^{-/-}$Opn $4^{-/-}$double null mice, even though the increased input from the rod pathway is still operating, there would be no partial depolarisation from melanopsin activation, and the cell would not reach threshold. It is noteworthy that previous studies involving $R e v-E r b \alpha^{-/-}$mice have also reported heightened responses to light. Much larger phase advances were seen in knockout compared to WT mice when exposed to a $2 \mathrm{~h}$ pulse of 500 lux light in the late night [20], and another study showed high amplitude phase resetting to 400 lux pulses in double mutant Rev-Erba ${ }^{-/} /$Per1 $^{\text {Brdm1 }}$ mice [35].

To see whether such hyper-sensitive light-mediated behavior could be due to changes in melanopsinergic input into the $\mathrm{SCN}$, we examined three non-mutually exclusive possibilities: numbers of melanopsin-immunopositive ipRGC, intensity of melanopsin expression in individual cells, and extent of ipRGC innervation of the SCN. We scored total ipRGC numbers in entire flat-mounted retinas, as well as the specific M1 ipRGC sub-population, using a validated melanopsin antibody that enabled immunodetection of the major sub-types within the GCL $[23,24]$. There were significantly more (62\%) total melanopsin-immunopositive ipRGC in Rev-Erba ${ }^{-/-}$ compared to WT mice, and the M1 sub-population [constituting $44 \%$ of the overall ipRGCs: 23] showed a roughly $75 \%$ increase in Rev-Erba ${ }^{-/}$compared to WT mice. 
By deduction the M2 sub-population [representing $50 \%$ of the total ipRGCs: 23] also increased by around $50 \%$. In addition to greater numbers, individual cell immunoreactivity was clearly more intense in knockout compared to WT retinas. However, qPCR analysis of Opn4 mRNA in both genotypes did not show any differences, and we were unable to prepare satisfactory western blots to measure protein levels. It is plausible that gene deletion affects generation or apoptosis rates of ipRGC, either directly or indirectly. The ipRGC undergo substantial apoptotic loss and remodelling during early postnatal development, postulated to be necessary for correct rod-cone input into the network [36]. As circadian clocks are strongly linked with cell cycle control and apoptosis [37], maybe these processes are modified in Rev-Erba ${ }^{-/}$mice, although gene deletion did not lead to changes in overall retinal cell numbers, including total cells within the GCL. We tested commercially available antibodies to REV-ERBa but were unable to obtain reliable images of co-localized REV-ERBa and melanopsin immunostaining to confirm a possible relationship between the two. A previous report successfully localized CLOCK, BMAL1, NPAS2, PER1, PER2 and CRY2 to ipRGC, but REV-ERBa was not tested [38]. Since early light history influences both ipRGC numbers [39] and light-mediated behaviour [40], the heightened light sensitivity in this strain may somehow modify these parameters indirectly. Despite the increase in ipRGC numbers in knockout mice, we could not detect any significant quantitative changes in innervation of the SCN between WT

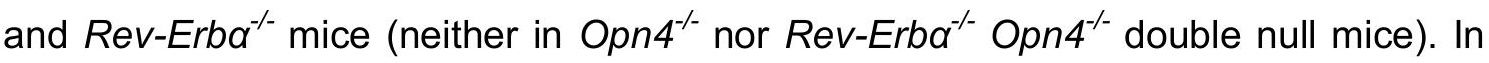
all genotypes CTB tracer showed robust coverage of the ventral SCN, and within the optic chiasma. Perhaps differences in axonal packing or size render the method of quantification (intensity and area of tracer within the $\mathrm{SCN}$ ) unable to visualize the increase. Taken together these data indicate significant modifications in the 
melanopsinergic system which would explain the higher sensitivity to light in knockout mice in the PLR, masking and jetlag experiments.

There were clear changes in light-driven responses seen in Rev-Erba ${ }^{-/}$ compared to WT mice, as measured by PLR, STR and scotopic and photopic ERGs. Compared to WT, Rev-Erba ${ }^{--}$mice tended to have smaller pupil areas in baseline conditions, and showed stronger PLR upon stimulation by a bright white light flash. While WT STR and single flash ERGs showed a predictable pattern of a small descending a-wave and large depolarising b-wave followed by a smooth return to baseline, traces in Rev-Erba ${ }^{-/-}$mice retinas differed in two ways: there were significantly decreased a- and b-wave latencies at virtually all stimulus intensities and a tendency towards higher b-wave amplitude at low stimulus intensities; and they showed abnormal "double humped" scotopic and photopic b-waves suggesting sustained signal elevation. There are at least two potential sources of such atypical signals: firstly, delayed sustained b-waves are seen in rod responses of mice deficient in hyperpolarisation-activated cyclic nucleotide (HCN) channels [41, 42]. Interestingly, HCN1 constitutes one of the clock-controlled genes expressed in retina, as revealed by transcription expression analysis of mouse eyes [5]. Secondly, previous reports have suggested ipRGCs themselves form a major component of the STR [28]. We speculate that the prolonged STR and ERG b-wave responses may also originate from the increased melanopsinergic content and activation. Future studies will address both these possibilities.

Within the molecular mechanism of the mammalian circadian clock, Rev-Erba transcription is driven by BMAL1/CLOCK heterodimers which bind to and activate Eboxes in the Rev-Erba promoter region [13, 20, 43, 44]. REV-ERBa in turn acts as a transcriptional repressor in a modulatory loop, providing negative feedback to the 
core positive loop composed of BMAL1 and CLOCK. Within the retina, we originally identified REV-ERBa as a direct interacting partner of the rod-specific transcription factor NR2E3, but in which it acts as a transcriptional activator leading to increased expression of the downstream target gene rhodopsin [17]. The data linking REVERBa localisation and function to rod photoreceptors [17-19, 45] led us to carefully examine possible changes in their number and phenotype in the Rev-Erba ${ }^{-/-}$mouse retina. However we could not find any differences in cell density or layer thickness, or changed expression levels of rhodopsin protein, or other photoreceptor and retinal neuronal markers.

In conclusion, these data collectively indicate that deletion of Rev-Erba leads to heightened sensitivity of the non-image forming pathway in the retina, with apparent involvement of the rod and/or ipRGC circuit. We do not yet know the mechanism underlying this hyper-sensitivity, though it is conceivable that increased numbers of ipRGCs and/or melanopsin expression levels would provide both increased capture of rod-mediated pathway input and enhanced delivery of visual information to the brain, and maybe feedback to inner retina through intra-retinal projections [46]. The retinal circadian clock is under intensive investigation due to its amenability [47], and there appears to be a finely regulated interplay between ipRGCs and the clock since it is known that circadian clock function is altered in Opn4-/- mice [48] and melanopsin expression itself is rhythmic [49]. We speculate that $R e v-E r b \alpha^{--}$plays an important role in fine-tuning retinal light sensitivity as a function of the light-dark cycle, and consistent with its transcriptional repressor activity, gene deletion leads to amplified sensitivity of the non-image forming pathway. The data are consistent with a major effect on ipRGCs, adding a further layer of complexity to an already intricately regulated network [50]. We feel the data 
presented here are more likely to reflect the true visual phenotype associated with Rev-Erba loss rather than the very different characteristics seen using shRNA interference technology [18]. The large differences between the two studies possibly come from the approach used here (total gene deletion) compared to partial siRNA knockdown, or to influences of endogenous transcription factors as modifiers [19]. Rev-Erba appears to be an important gene for retinal function, since other reported clock gene mutations present relatively mild retinal phenotypes: the $B m a / 1^{-1-}$ mouse exhibits a $\sim 30 \%$ decrease in scotopic ERG b-wave amplitude [5]; and double clock gene mutant Per1 $1^{\text {Brdm1 } 1} /$ Per2 ${ }^{\text {Brdm1 }}$ mice exhibit slightly delayed photoreceptor differentiation and alterations in short wavelength cone distribution [30], but do not exhibit behavioural changes in light sensitivity (unpublished observations). 


\section{References}

1. Tosini, G., and Menaker, M. (1996) Circadian rhythms in cultured mammalian retina. Science $\mathbf{2 7 2}, 419-421$.

2. Ko, G.Y., Ko, M.L., and Dryer, S.E. (2001) Circadian regulation of cGMP-gated cationic channels of chick retinal cones. Erk MAP Kinase and Ca2+/calmodulin-dependent protein kinase II. Neuron 2, 255-266.

3. Ribelayga, C., Cao, Y., and Mangel, S.C. (2008) The circadian clock in the retina controls rod-cone coupling. Neuron 59, 790-801.

4. LaVail, M.M. (1980) Circadian nature of rod outer segment disc shedding in the rat. Invest Ophthalmol Vis Sci 19, 407-411.

5. Storch, K.F., Paz, C., Signorovitch, J., Raviola, E., Pawlyk, B., Li, T., and Weitz, C.J. (2007) Intrinsic circadian clock of the mammalian retina: importance for retinal processing of visual information. Cell 130, 730-741.

6. Berson, D.M. (2003) Strange vision: ganglion cells as circadian photoreceptors. Trends Neurosci 26, 314-320.

7. Hankins, M.W., Peirson, S.N., and Foster, R.G. (2008) Melanopsin: an exciting photopigment. Trends Neurosci 31, 27-36.

8. Hannibal, J., and Fahrenkrug, J. (2004) Target areas innervated by PACAPimmunoreactive retinal ganglion cells. Cell Tissue Res 316, 99-113.

9. Ecker, J.L., Dumitrescu, O.N., Wong, K.Y., Alam, N.M., Chen, S.K., LeGates, T., Renna, J.M., Prusky, G.T., Berson, D.M., and Hattar, S. (2010) Melanopsin-expressing retinal ganglion-cell photoreceptors: cellular diversity and role in pattern vision. Neuron 67, 49-60. 
10. Lucas, R.J., Hattar, S., Takao, M., Berson, D.M., Foster, R.G., and Yau, K.W. (2003) Diminished pupillary light reflex at high irradiances in melanopsinknockout mice. Science 299, 245-7.

11. Hattar, S., Lucas, R.J., Mrosovsky, N., Thompson, S., Douglas, R.H., Hankins, M.W., Lem, J., Biel, M., Hofmann, F., Foster, R.G., and Yau, K.W. (2003) Melanopsin and rod-cone photoreceptive systems account for all major accessory visual functions in mice. Nature $\mathbf{4 2 4}, 76-81$.

12. Mrosovsky, N., and Hattar, S. (2003) Impaired masking responses to light in melanopsin-knockout mice. Chronobiol Int 20, 989-999.

13. Ko, C.H., and Takahashi, J.S. (2006) Molecular components of the mammalian circadian clock. Hum Mol Genet 15, R271-277.

14. Albrecht, U. (2010) Circadian clocks in mood-related behaviors. Ann Med 42, 241-251.

15. Ruan, G.X., Zhang, D.Q., Zhou, T., Yamazaki, S., and McMahon, D.G. (2006) Circadian organization of the mammalian retina. Proc Natl Acad Sci USA 103, 9703-9708.

16. Jaeger, C., Sandu, C., Malan, A., Mellac, K., Hicks, D., and FelderSchmittbuhl, M.P. (2015) Circadian organization of the rodent retina involves strongly coupled, layer-specific oscillators. FASEB J 29, 1493-504.

17. Cheng, H., Khanna, H., Oh, E.C., Hicks, D., Mitton, K.P., and Swaroop, A. (2004) Photoreceptor-specific nuclear receptor NR2E3 functions as a transcriptional activator in rod photoreceptors. Hum Mol Genet 13, 1563-1575.

18. Mollema, N.J., Yuan, Y., Jelcick, A.S., Sachs, A.J., von Alpen, D., Schorderet, D., Escher, P., and Haider, N.B. (2011) Nuclear receptor Rev-erb alpha 
(Nr1d1) functions in concert with Nr2e3 to regulate transcriptional networks in the retina. PLoS One 6, e17494.

19. Cruz, N.M., Yuan, Y., Leehy, B.D., Baid, R., Kompella, U., DeAngelis, M.M., Escher, P., and Haider, N.B.. (2014) Modifier genes as therapeutics: the nuclear hormone receptor Rev Erb alpha (Nr1d1) rescues Nr2e3 associated retinal disease. PLoS One 9, e87942.

20. Preitner, N., Damiola, F., Lopez-Molina, L., Zakany, J., Duboule, D., Albrecht, U., and Schibler, U. (2002) The orphan nuclear receptor REV-ERBalpha controls circadian transcription within the positive limb of the mammalian circadian oscillator. Cell 110, 251-260.

21. Ruby, N.F., Brennan, T.J., Xie, X., Cao, V., Franken, P., Heller, H.C., and O'Hara, B.F. (2002) Role of melanopsin in circadian responses to light. Science 298, 2211-3.

22. Mrosovsky, N. (1999) Masking: history, definitions, and measurement. Chronobiol Int 16, 415-429.

23. Karnas, D., Mordel, J., Bonnet, D., Pevet, P., Hicks, D., and Meissl, H. (2013) Heterogeneity of intrinsically photosensitive retinal ganglion cells in the mouse revealed by molecular phenotyping. J Comp Neurol 521, 912-32.

24. Provencio, I., Rollag, M.D., and Castrucci, A.M. (2002) Photoreceptive net in the mammalian retina. This mesh of cells may explain how some blind mice can still tell day from night. Nature 415, 493.

25. Do, M.T., Kang, S.H., Xue, T., Zhong, H., Liao, H.W., Bergles, D.E., and Yau, K.W. (2009) Photon capture and signalling by melanopsin retinal ganglion cells. Nature 457, 281-7. 
26. Jaissle, G.B., May, C.A., Reinhard, J., Kohler, K., Fauser, S., Lutjen-Drecoll, E., Zrenner, E., and Seeliger, M.W. (2001) Evaluation of the rhodopsin knockout mouse as a model of pure cone function. Invest Ophthalmol Vis Sci 42, 506-513.

27. Boudard, D.L., Acar, N., Bretillon, L., and Hicks, D. (2011) Retinas of the diurnal rodent Arvicanthis ansorgei are highly resistant to experimentally induced stress and degeneration. Invest Ophthalmol Vis Sci 52, 8686-8700.

28. Pérez de Lara, M.J., Santano, C., Guzmán-Aránguez, A., Valiente-Soriano, F.J., Avilés-Trigueros, M., Vidal-Sanz, M., de la Villa, P., and Pintor, J. (2014) Assessment of inner retina dysfunction and progressive ganglion cell loss in a mouse model of glaucoma.

29. Kostic, C., Crippa, S.V., Martin, C., Kardon, R.H., Biel, M., Arsenijevic, Y., and Kawasaki, A. (2016) Determination of Rod and Cone Influence to the Early and Late Dynamic of the Pupillary Light Response. Invest Ophthalmol Vis Sci $57,2501-8$

30. Ait-Hmyed, O., Felder-Schmittbuhl, M.P., Garcia-Garrido, M., Beck, S., Seide, C., Sothilingam, V., Tanimoto, N., Seeliger, M., Bennis, M., and Hicks, D. (2013) Mice lacking Period 1 and Period 2 circadian clock genes exhibit blue cone photoreceptor defects. Eur J Neurosci 37, 1048-60.

31. Hughes, W.F. (1990) Quantitation of ischemic damage in the rat retina. Exp Eye Res 53, 573-582.

32. Hicks, D., and Molday, R.S. (1986) Differential immunogold-dextran labeling of bovine and frog rod and cone cells using monoclonal antibodies against bovine rhodopsin. Exp Eye Res 42, 55-71.

Exp Eye Res 122, 40-9. 
33. Hellemans, J., Mortier, G., De Paepe, A., Speleman, F., and Vandesompele, J. (2007) qBase relative quantification framework and software for management and automated analysis of real-time quantitative PCR data. Genome Biol 8, R1

34. Do MT, Yau KW. (2010) Intrinsically photosensitive retinal ganglion cells. Physiol Rev 90,1547-81.

35. Jud, C., Hayoz, A., and Albrecht, U. (2010) High amplitude phase resetting in rev-erbalpha/per1 double mutant mice. PLoS One 5, e12540.

36. Chen, S.K., Chew, K.S., McNeill, D.S., Keeley, P.W., Ecker, J.L., Mao, B.Q., Pahlberg, J., Kim, B., Lee, S.C., Fox, M.A., Guido, W., Wong, K.Y., Sampath, A.P., Reese, B.E., Kuruvilla, R., and Hattar, S. (2013) Apoptosis regulates ipRGC spacing necessary for rods and cones to drive circadian photoentrainment. Neuron 77, 503-15.

37. Granda, T.G., Liu, X.H., Smaaland, R., Cermakian, N., Filipski, E., SassoneCorti, P., and Levi, F. (2005) Circadian regulation of cell cycle and apoptosis proteins in mouse bone marrow and tumor. FASEB J 19, 304-306.

38. Liu, X., Zhang, Z., and Ribelayga, C.P. (2012) Heterogeneous expression of the core circadian clock proteins among neuronal cell types in mouse retina. PLOS ONE 7, e50602.

39. Hong, J., Zeng, Q., Wang, H., Kuo, D.S., Baldridge, W.H., and Wang, N. (2013) Controlling the number of melanopsin-containing retinal ganglion cells by early light exposure. Exp Eye Res 111, 17-26.

40. Cambras, T., Canal, M.M., Cernuda-Cernuda, R., García-Fernández, J.M., and Díez-Noguera, A. (2015) Darkness during early postnatal development is required for normal circadian patterns in the adult rat. Chronobiol Int 32, 17886. 
41. Knop, G.C., Seeliger, M.W., Thiel, F., Mataruga, A., Kaupp, U.B., Friedburg, C., Tanimoto, N., and Müller, F. (2008) Light responses in the mouse retina are prolonged upon targeted deletion of the $\mathrm{HCN} 1$ channel gene. Eur $\mathrm{J}$ Neurosci 28, 2221-30.

42. Sothilingam, V., Michalakis, S., Garcia Garrido, M., Biel, M., Tanimoto, N., and Seeliger, M.W. (2016) HCN1 Channels Enhance Rod System Responsivity in the Retina under Conditions of Light Exposure. PLoS One 11, e0147728.

43. Guillaumond, F., Dardente, H., Giguère, V., and Cermakian, N. (2005) Differential control of Bmal1 circadian transcription by REV-ERB and ROR nuclear receptors. J Biol Rhythms 20, 391-403.

44. Duez, H., and Staels, B. (2009) Rev-erb-alpha: an integrator of circadian rhythms and metabolism. J Appl Physiol 107, 1972-80.

45. Haider, N.B., Mollema, N., Gaule, M., Yuan, Y., Sachs, A.J., Nystuen, A.M., Naggert, J.K., and Nishina, P.M. (2009) Nr2e3-directed transcriptional regulation of genes involved in photoreceptor development and cell-type specific phototransduction. Exp Eye Res 89, 365-372.

46. Zhang, D.Q., Belenky, M.A., Sollars, P.J., Pickard, G.E., and McMahon, D.G. (2012) Melanopsin Mediates Retrograde Visual Signaling in the Retina. PLoS One 7, e42647.

47. Dkhissi-Benyahya, O., Coutanson, C., Knoblauch, K., Lahouaoui, H., Leviel, V., Rey, C., Bennis, M., and Cooper, H.M. (2013) The absence of melanopsin alters retinal clock function and dopamine regulation by light. Cell Mol Life Sci 70, 3435-47. 
48. McMahon, D.G., luvone, P.M., and Tosini, G. (2014) Circadian organization of the mammalian retina: from gene regulation to physiology and diseases. Prog Retin Eye Res 39, 58-76.

49. Sakamoto, K., Liu, C., and Tosini, G. (2004) Classical photoreceptors regulate melanopsin mRNA levels in the rat retina. J Neurosci 24, 9693-9697.

50. Schmidt, T.M., Chen, S.K., and Hattar, S. (2011) Intrinsically photosensitive retinal ganglion cells: many subtypes, diverse functions. Trends Neurosci 34, 572-580. 


\section{Figure Legends}

Figure 1: Rev-Erb $\alpha^{-/}$mice show enhanced negative masking light responses compared to WT mice. A. General motor activity was plotted as actograms during the LD cycle (night indicated by black rectangles above actograms). Both strains $(n=6)$ were subjected to an alternating lighting regime of normal 12/12 LD cycle followed by an LD cycle during which a $3 \mathrm{~h}$ light pulse was delivered during the early dark period, from ZT14-ZT17 (ZT12 represents lights off). An entire experimental series was designed as follows: first day, normal 12/12 LD cycle; second day, 12 L/0.1 lux light pulse from ZT14-17 during night period; third day, normal 12/12 LD cycle; fourth day, 12 L/22 lux light pulse from ZT14-17 during night period; fifth day, normal 12/12 LD cycle; sixth day, 12 L/100 lux light pulse from ZT14-17 during night period. The design is shown with shaded yellow boxes at the corresponding time for each genotype, deeper yellow corresponding to brighter light. Whereas all three intensities inhibited motor activity in Rev-Erb $\alpha^{-/-}$mice, the dim light pulse (0.1 lux) did not induce negative masking in WT mice. The figure shows a representative trace from individual mice of both strains. B. The difference in masking behavior was statistically significant when analyzed by ANOVA. Whereas WT and Rev-Erb $\alpha^{-/}$mice showed similar levels of activity during 100 (WT: 46\%, Rev-Erb $\alpha^{--}: 39 \%$ dark levels) and 22 (WT: $75 \%$, Rev-Erbo $\alpha^{--}: 61 \%$ dark levels) lux light pulses, WT mice showed significantly more activity (180\%) compared to Rev-Erb $\alpha^{--}$(62\% dark levels) at 0.1 lux. ${ }^{*}, P<0.05$.

Figure 2: Rev-Erb $\alpha^{-/}$mice display increased melanopsin expression. A) When flatmounts of retinas from WT (left) and Rev-Erb $\alpha^{-/-}$(right) mice were immunostained for melanopsin, at the same incubation and photographic exposure time the knockout retinas showed clearly enhanced immunofluorescence, with distinct demarcation of 
cell bodies and dendrites. The soma location and level of dendrite arborisation indicates these are M1 type ipRGC. B) Quantification of total immunostained ipRGC ( $n=5$ retinas each genotype) showed a highly significant increase (62\%) in knockout retinas. ${ }^{*}=p<0.05$. C) Quantification of M1 sub-type ipRGC (more intensely immunostained, somata located more superficially) ( $n=5$ retinas each genotype) showed a highly significant increase $(75 \%)$ in knockout retinas. ${ }^{*}=p<0.05$. D) Exposure to a 0.1 lux light pulse during the night phase of a 12L/12D cycle (ZT14-17)

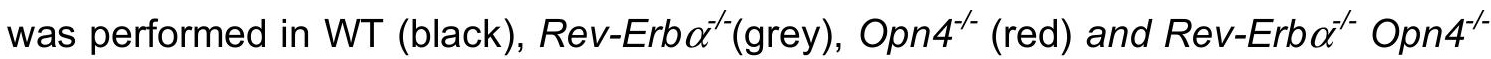
(blue) mice. Only the Rev-Erbo $\alpha^{-/}$mice display negative masking behaviour, with a $64 \%$ reduction in locomotor activity with respect to dark levels $\left({ }^{*}, P<0.05, \mathrm{n}=4-5\right.$ per genotype). E). General locomotor activity is shown for each of the four genotypes across the entire dark period and during the 0.1 lux pulse. It can be seen that the Rev-Erb $\alpha^{-/}$mouse (grey trace) rapidly decreased activity upon light exposure, whereas WT (black trace)and Opn $4^{-/}$(red) mice showed small positive masking effects; double Rev-Erb $\alpha^{-/}$Opn $4^{-/}$(blue) mice did not alter their behaviour during the light pulse.

Figure 3. Rev-Erb $\alpha^{--}$mice display increased pupillary light reflexes and altered scotopic threshold responses compared to WT mice. A) Representative pictures of pupils of WT $(\mathrm{n}=7)$ and Rev-Erb $\alpha^{--}(\mathrm{n}=6)$ mice taken using an infrared camera. WT mice displayed larger pupil dilation after dark adaptation. Following illumination, both strains showed pupil constriction and a subsequent slow dilation until $20 \mathrm{sec}$ after light stimulus. B) Absolute pupil diameter of WT $(n=7)$ and Rev-Erb $\alpha^{-1-}(n=6)$ mice before light stimulation. C) Pupillary constriction curve responses of WT $(n=7)$ and $\operatorname{Rev}-\operatorname{Erb}^{-/-}(\mathrm{n}=6)$ mice. Rev-Erb $\alpha^{-/}$mice displayed a different pattern of pupil dilation characterized by a more sustained constriction. D) STRs from Rev-Erb $\alpha^{-/-}$mice were 
characterized by a hump-shaped distortion at implicit times corresponding to the nSTR response. The magnitude of this hump was not related to stimulus intensity. E) positive STR (pSTR) amplitudes of WT $(n=7)$ and Rev-Erb $\alpha^{-/-}(n=6)$ mice. The amplitude of pSTR response at a stimulus intensity of $3 \times 10^{-5} \mathrm{mcds} / \mathrm{m}^{2}$ $(\log$ (intensity) $=-4.60)$ was significantly higher in Rev-Erb $\alpha^{-/-}$when compared to WT animals ( $p<0.05$, Two-tailed Student's t-test). No difference between the two groups of animals was observed for pSTRs at stimulus intensities of $6 \times 10^{-5}$ and $9 \times 10^{-5}$ $\mathrm{mcds} / \mathrm{m}^{2}(\log$ (intensity)=-4.20 and -4.02 , respectively). Black traces, WT; grey traces, Rev-Erbo $\alpha^{-/}$.

Figure 4: Light-evoked ERG responses are modified in Rev-Erb $\alpha^{-/}$compared to WT mice. A) When compared to WT (left panel, black traces), Rev-Erb $\alpha^{-/-}$mice (middle panel, red traces) were characterized by a humped distortion on the descending bwave trace. The two traces are shown super-imposed in the right panel. The magnitude of this hump was variable between knock-out mice. Rev-Erb $\alpha^{-/-}$mice also displayed shortened implicit times in the ERG b-wave $\left({ }^{*}\right.$, right panel). B) In comparison to littermate WT controls, dark-adapted b-wave latency was significantly reduced in $\operatorname{Rev-Erb} \alpha^{-/}$mice ( $P=0.048$, two-way ANOVA, repeated measures). C) Focus on a- and b-wave forms. The light-activated photoreceptor hyperpolarizing response (a-wave) was shifted to the left in Rev-Erb $\alpha^{-/}$(red) compared to WT (black). Similarly, the depolarising rise of the b-wave is also advanced. The traces presented here were obtained at a light stimulation at $2500 \mathrm{mcds} / \mathrm{m}^{2}$. D) This shortening of the photoreceptor response was confirmed by measuring the implicittime of the ERG a-wave, which also proved significantly decreased with respect to WT mice ( $P=0.02$, two-way ANOVA with repeated measures). E) When compared to control animals, Rev-Erb $\alpha^{--}$mice showed a tendency to display higher scotopic b- 
wave amplitudes, without reaching statistical significance. F) Such a tendency was not observed for the scotopic a-wave amplitude. G) A hump similar to that observed on dark-adapted scotopic responses was also present on the descending part of the b-wave of light-adapted photopic ERG traces. For WT animals in panels B, D, E, F, the area delimiting $5 \%$ and $95 \%$ quantiles is represented by the two black lines. For Rev-Erb $\alpha^{--}$mice, the graphs make use of box-and-whisker-plots showing $5 \%$ and 95\% quantiles (whiskers), $25 \%$ and $75 \%$ quartiles (grey box), and the median value (marked by a cross).

Figure 5: WT and Rev-Erbo ${ }^{-/}$mice retinas do not differ in terms of structure or photoreceptor phenotype. A) Examination of histological sections of WT (left) or Rev$E r b \alpha^{-/}$(right) retinas ( $\mathrm{n}=3$ animals per genotype) revealed similar cell layer thicknesses and numbers. This was confirmed by quantification of cell densities (B) and layer thickness (C). D-H) Different antibody markers of rod and cone photoreceptors also did not show differences between the two genotypes: top row, WT; bottom row, Rev-Erb $\alpha^{-/-}$mice. D) DAPI staining of total nuclei; E) anti-rhodopsin (Rho) staining, visible as intense label within the rod outer segments (OS) and surrounding the cell bodies in the outer nuclear layer (ONL); F) anti-mid wavelength sensitive cone opsin (MW COp) staining, present within the cone OS; G) anti-short wavelength sensitive cone opsin (SW COp) staining, present within a subset of cone OS; H) WT and Rev-Erb $\alpha^{-/-}$mice retinas immunostained with anti-PKCa antibody. In both cases the labelling was visible throughout ON bipolar cells, extending from postsynaptic elements in the OPL through the cell bodies till the synaptic terminals in the INL. Additional abbreviations: $\mathrm{GCL}=$ ganglion cell layer, INL= inner nuclear layer, IPL = inner plexiform layer, IS = inner segments. I) Rhodopsin expression was assayed by western blotting and showed similar levels in both genotypes. Scale bar in panel 
$=20 \mu \mathrm{m}$ for $\mathrm{A} ; 60 \mu \mathrm{m}$ for $\mathrm{E}-\mathrm{H} \mathrm{I} ; 30 \mu \mathrm{m}$ for I. J) qPCR analysis of Opn4 mRNA expression levels in WT and Rev-Erb $\alpha^{-/}$mouse retinas. There was no significant difference between the two groups.

Figure 6: Schematic diagram of hypothetical mechanism. Output of ipRGC is a summation of rod and cone synaptic input and melanopsin stimulation. Under strong light conditions, sufficient drive from one or other components will depolarise ipRGCs and lead to firing. Under faint light, WT ipRGCs will not be sufficiently stimulated and remain silent, though the cells are partly depolarised and exhibit resting potentials close to threshold. Rev-Erb $\alpha^{-/}$mice display enhanced synaptic input from the rod pathway, coupled with increased melanopsin content in individual ipRGCs, sufficient to lead to ipRGC firing. Although such increased rod drive is also present in double Rev-Erba ${ }^{-/} \mathrm{Opn} 4^{-/}$mice, the absence of partial contribution from melanopsin stimulation results in the cells remaining at sub-threshold potentials. Opn $4^{-/}$mice also fail to elicit firing for the same reasons. The number of "+" indicates the hypothetical level of stimulation. $\mathrm{R}=\mathrm{rod}, \mathrm{C}=$ cone, $\mathrm{G}=\mathrm{ipRGC}$. Curved arrow between rods and cones, and ipRGC, indicates bipolar contact. 
A

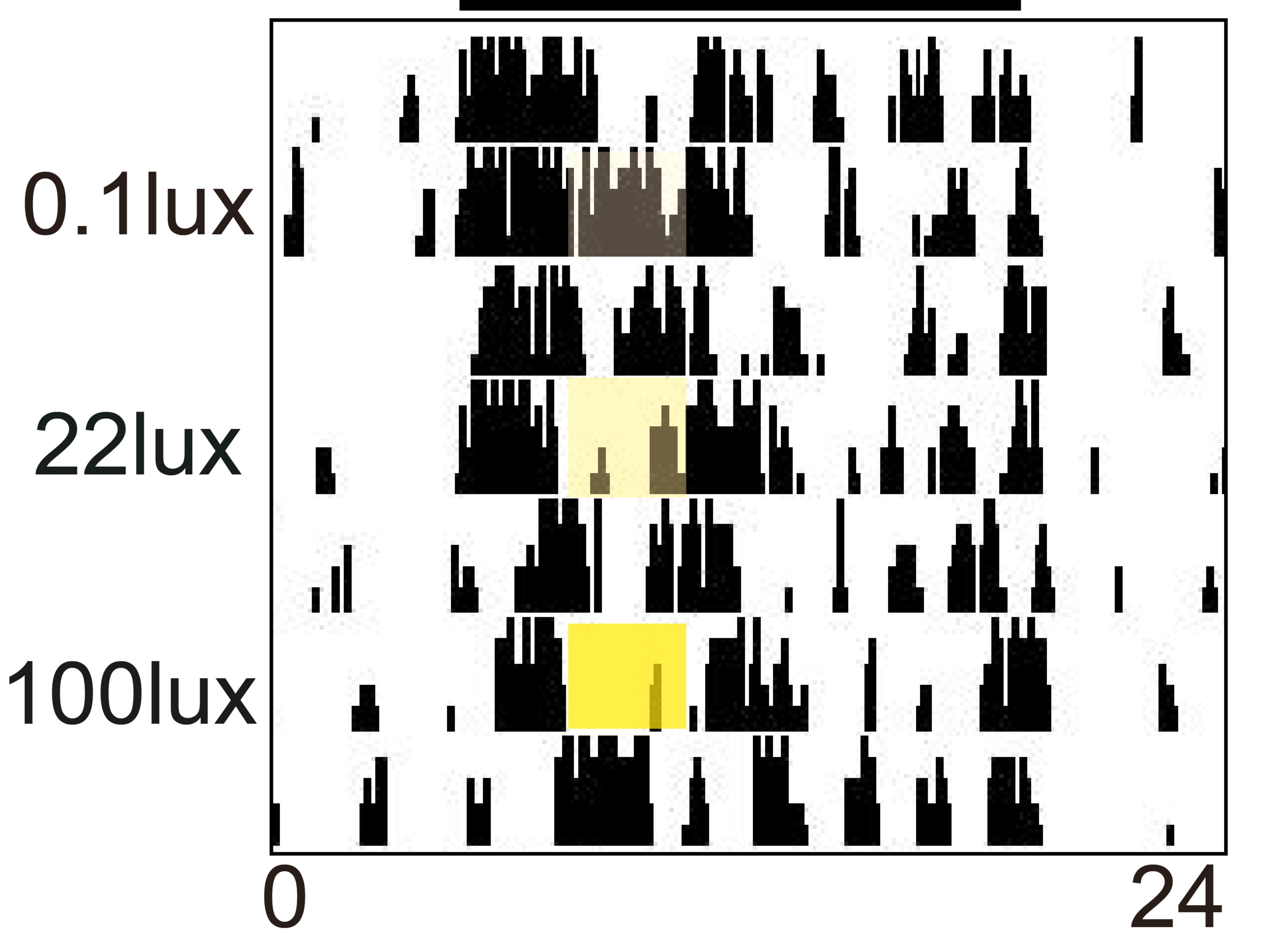

Time (hours)

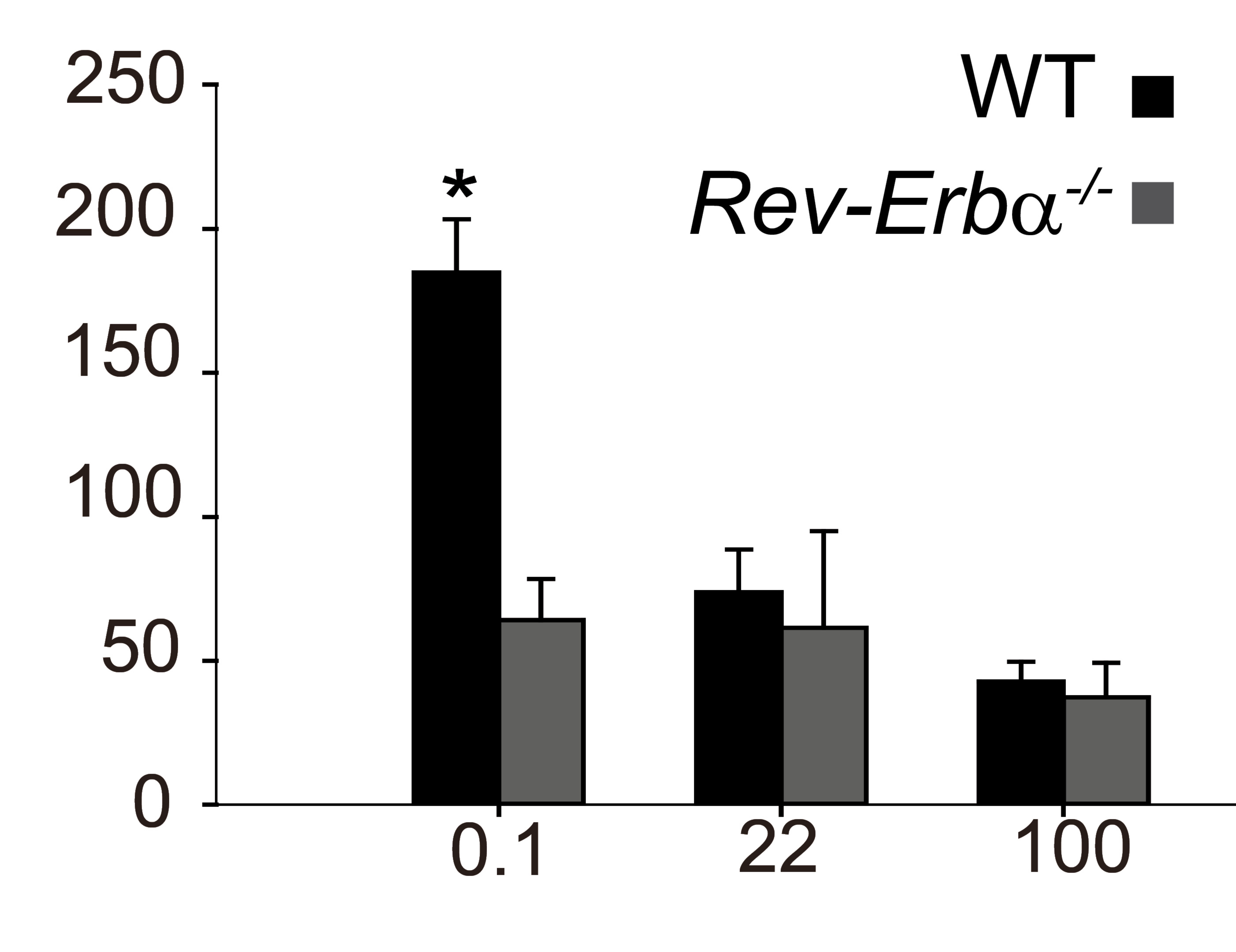

Intensity (lux)

Figure 1 
A

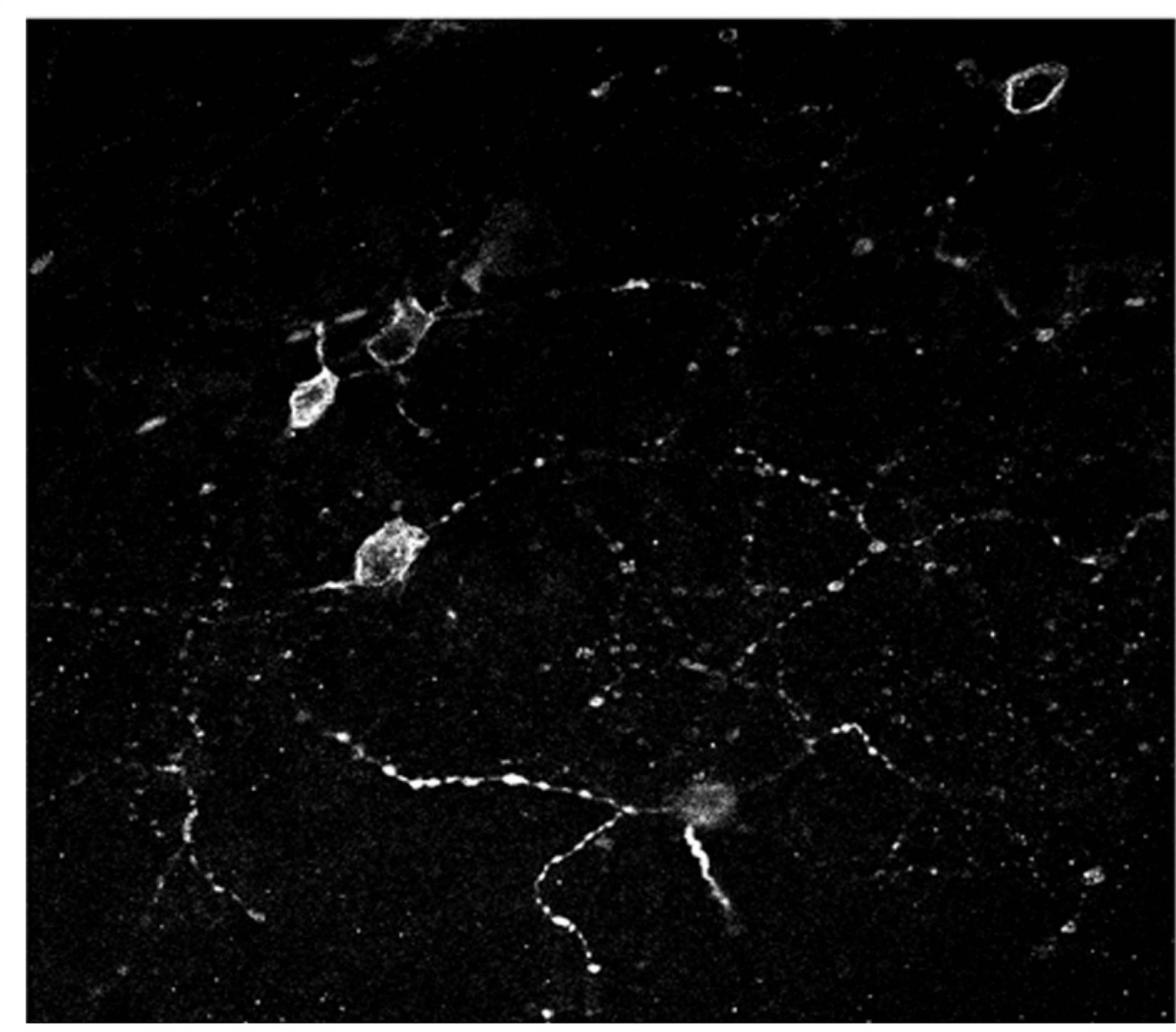

WT

B

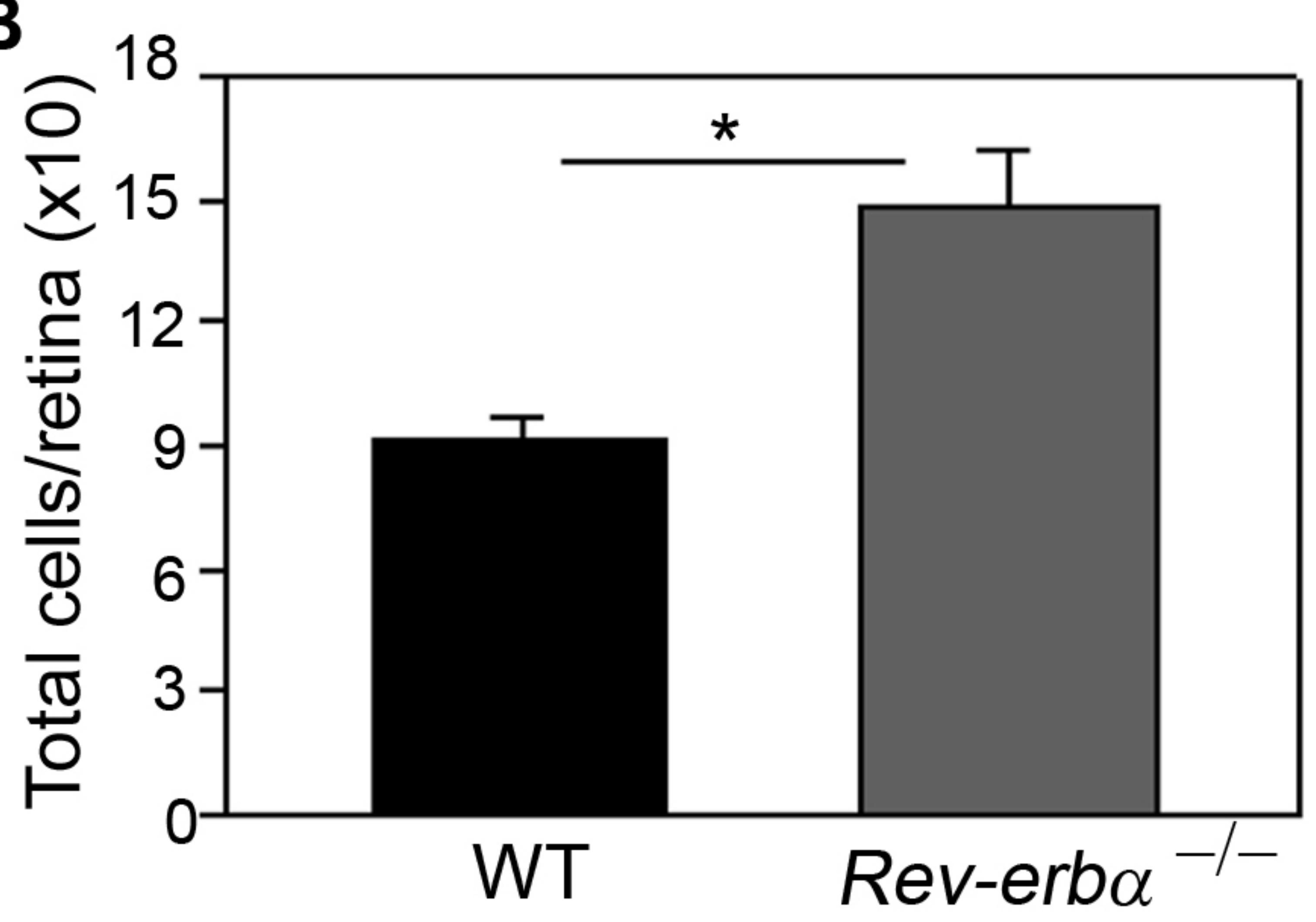

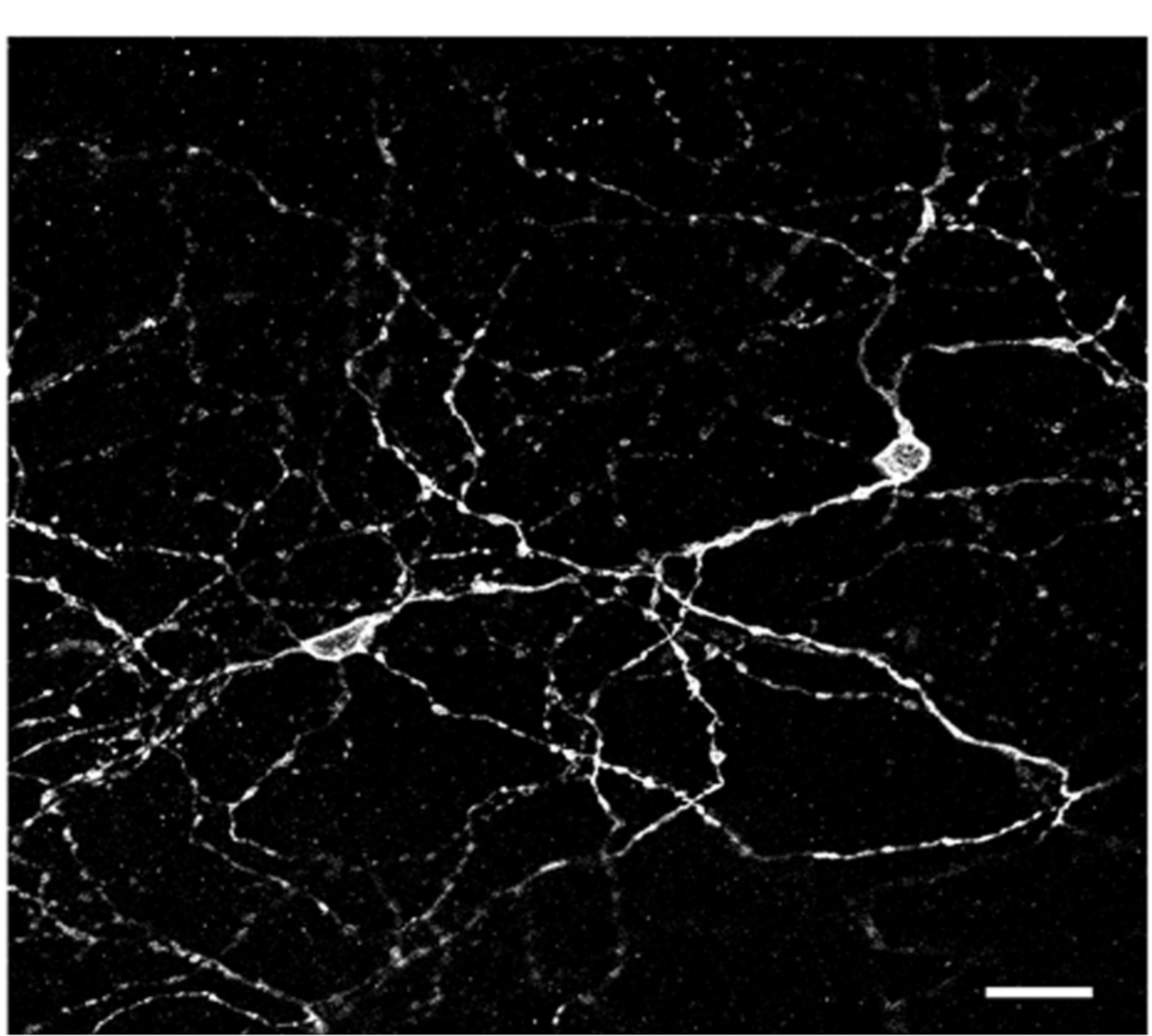

Rev-erb $\alpha^{-/-}$

C

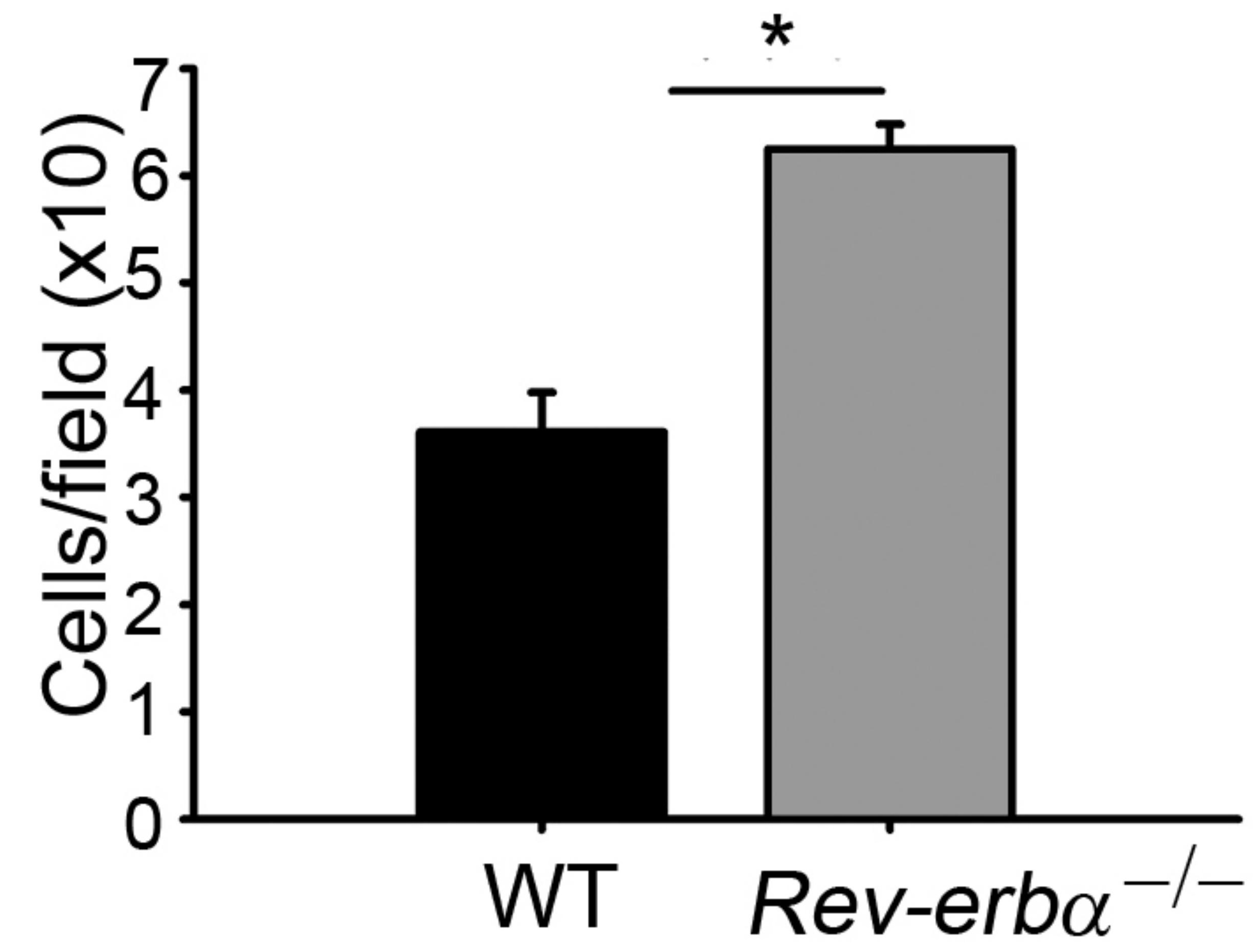

D

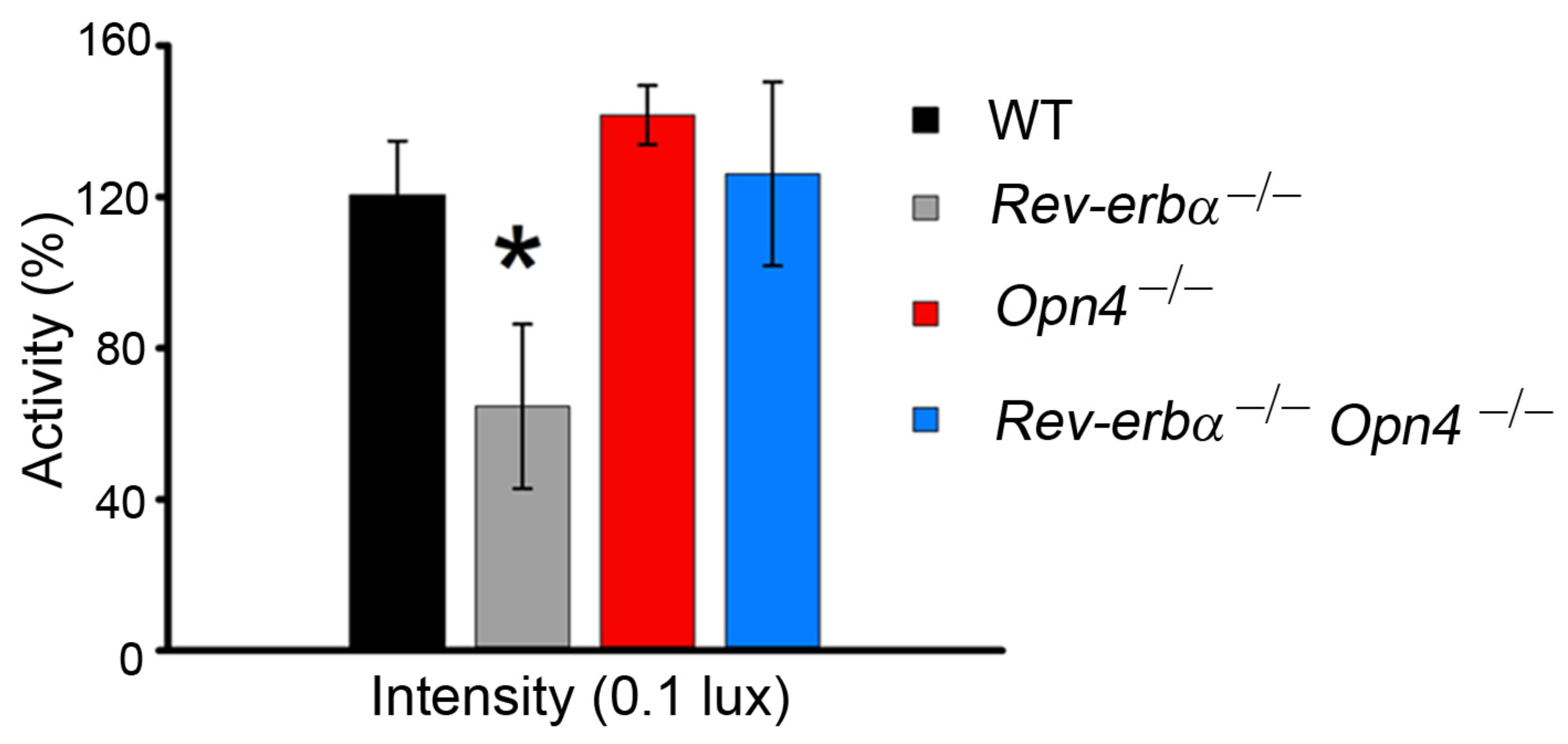

E

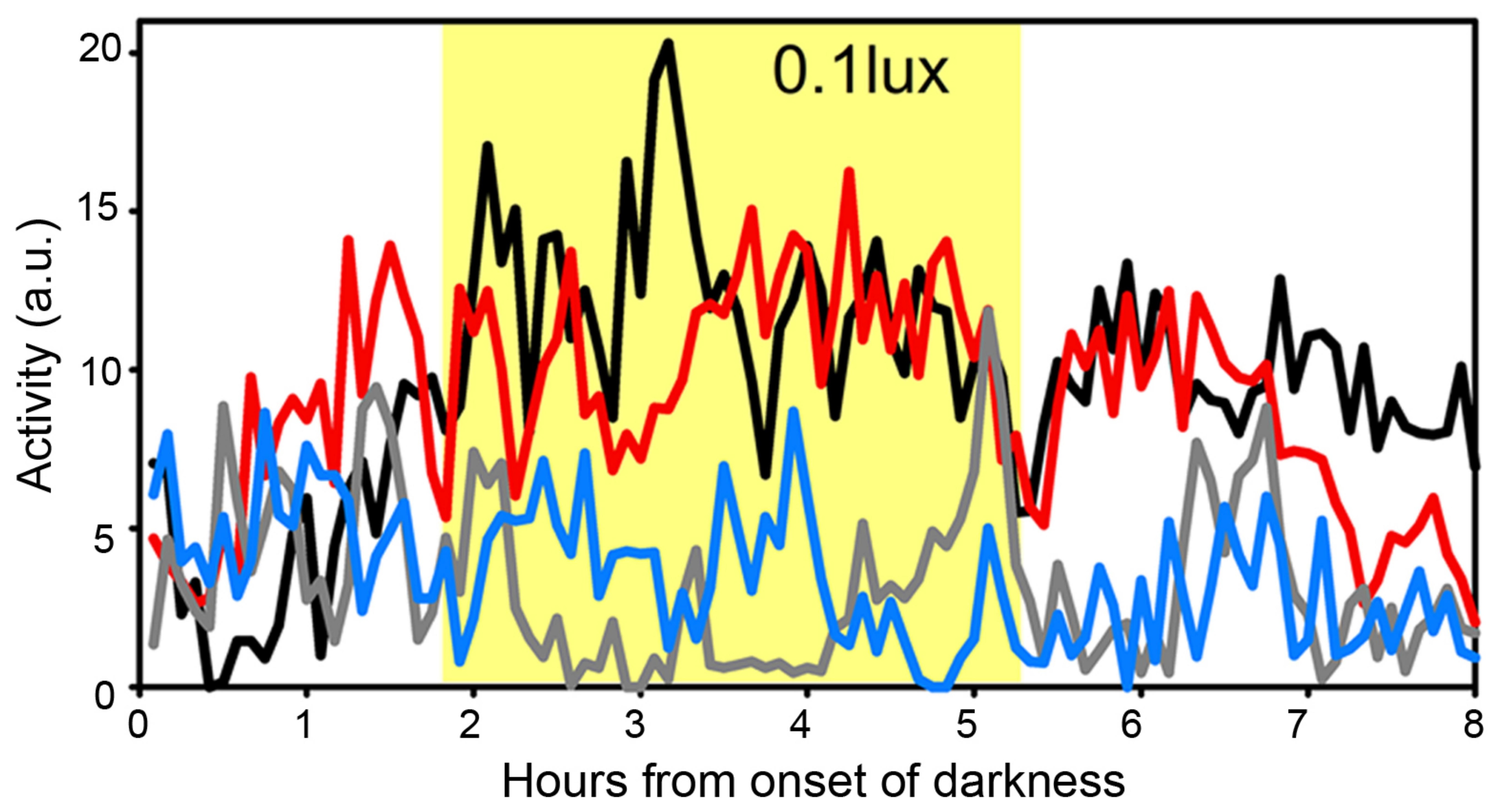


A
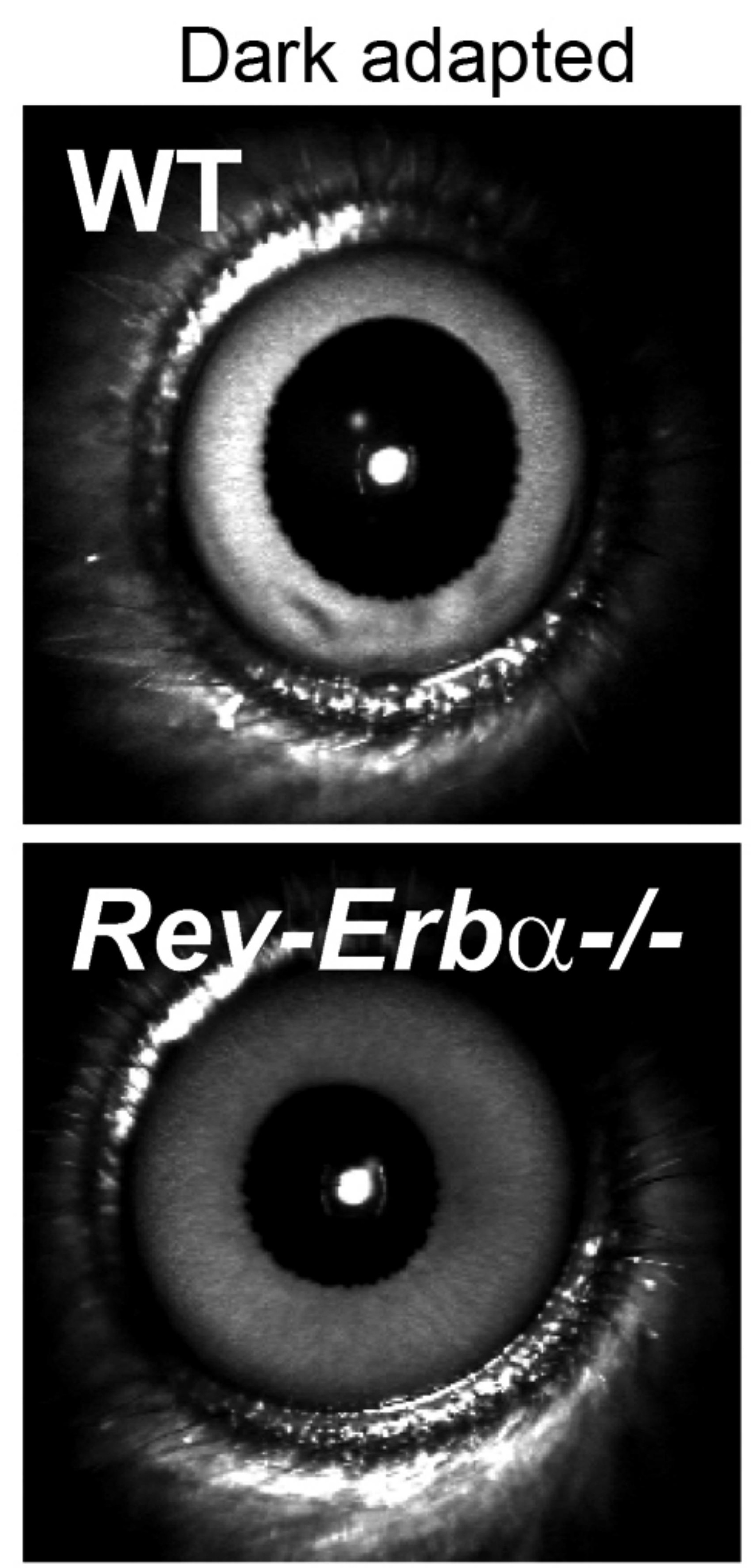

B

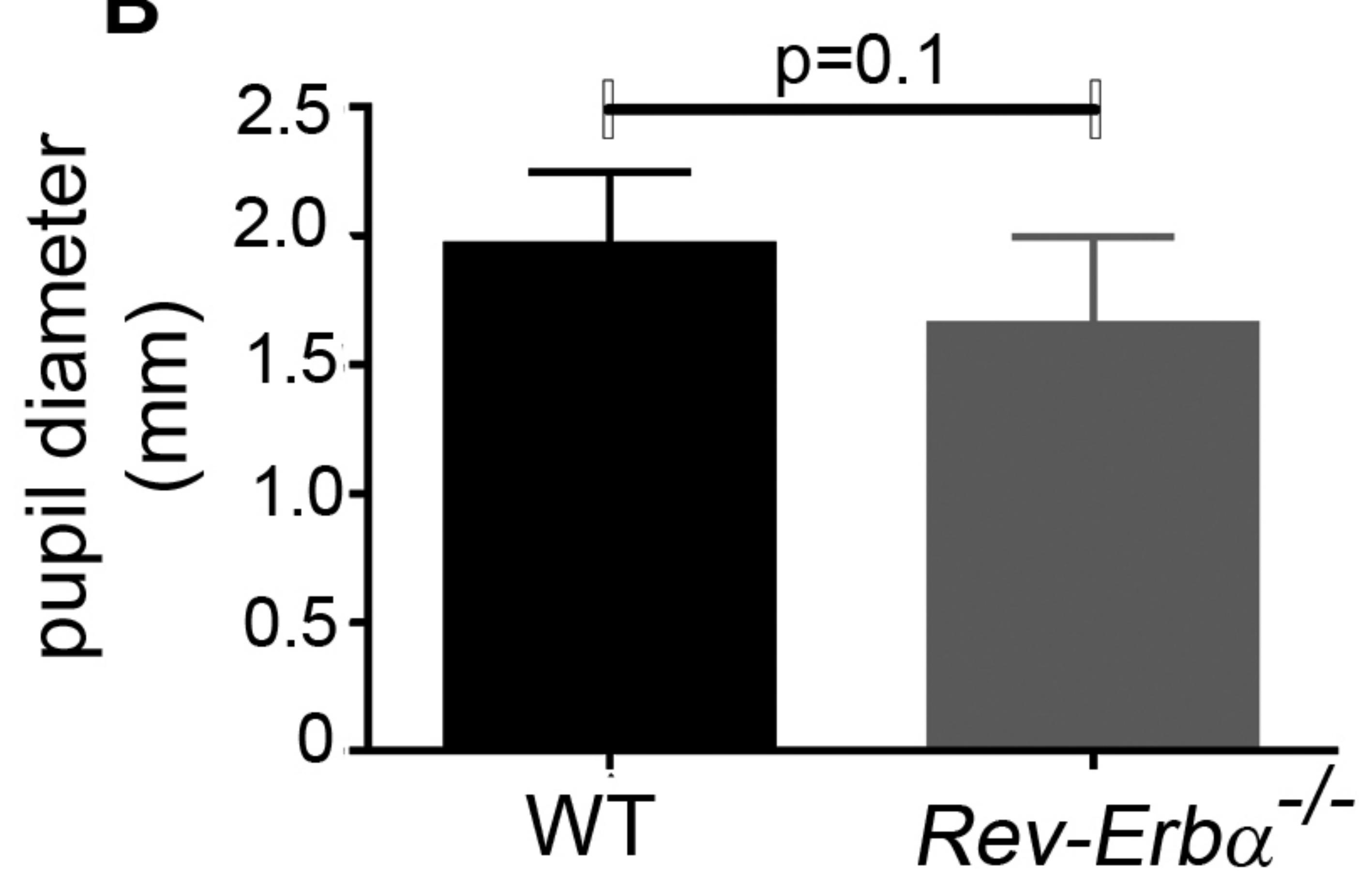

D

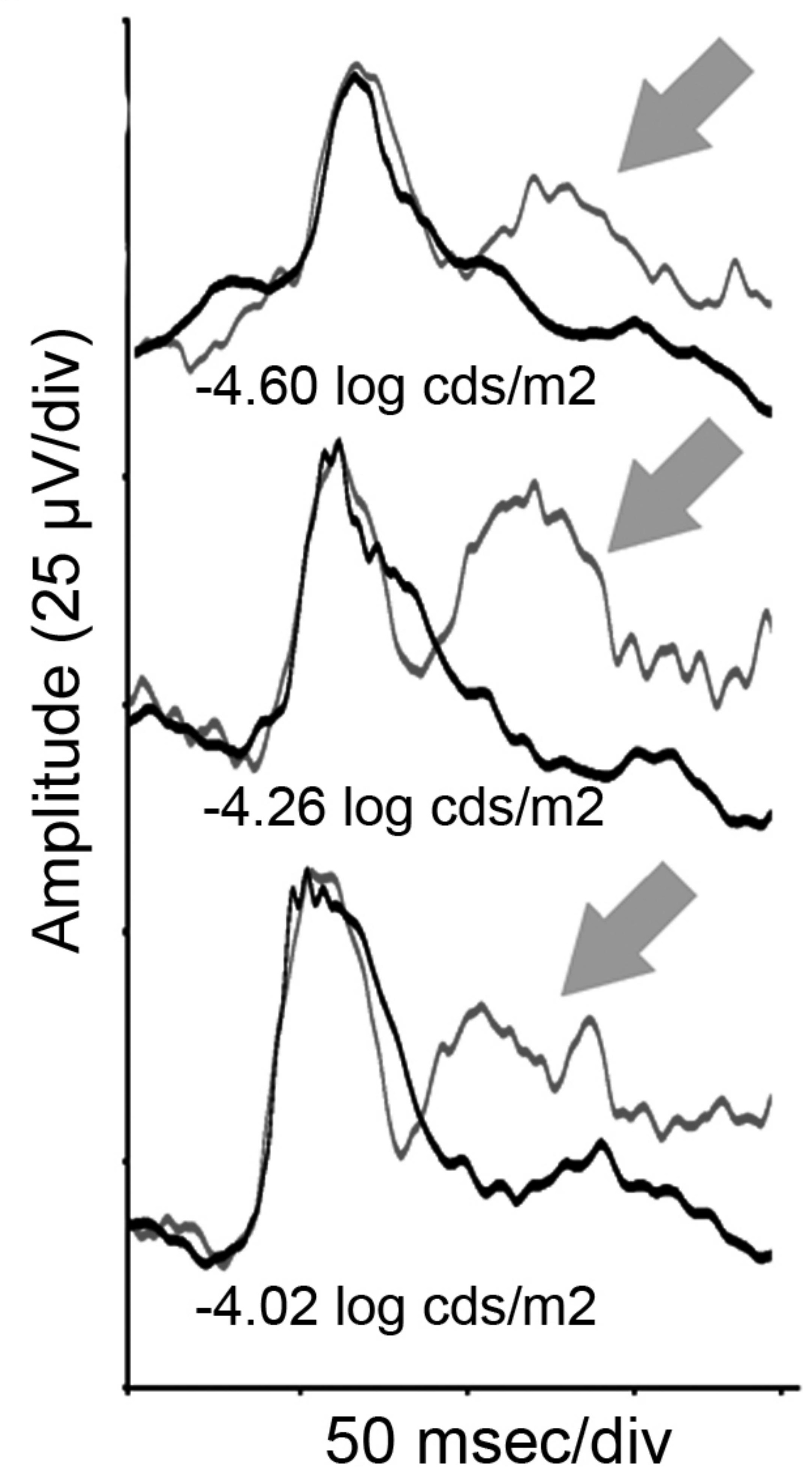

Max. constriction
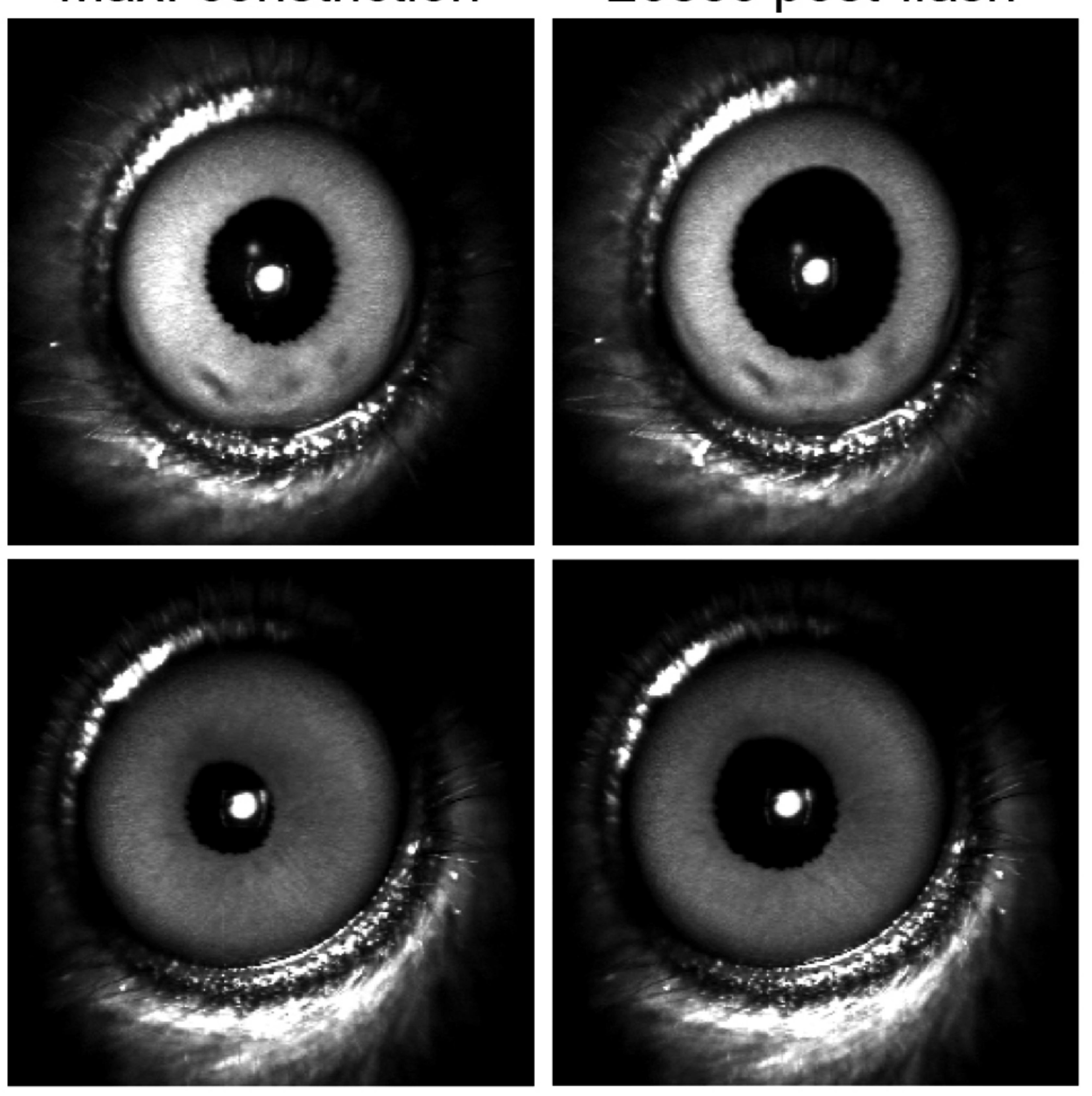

C
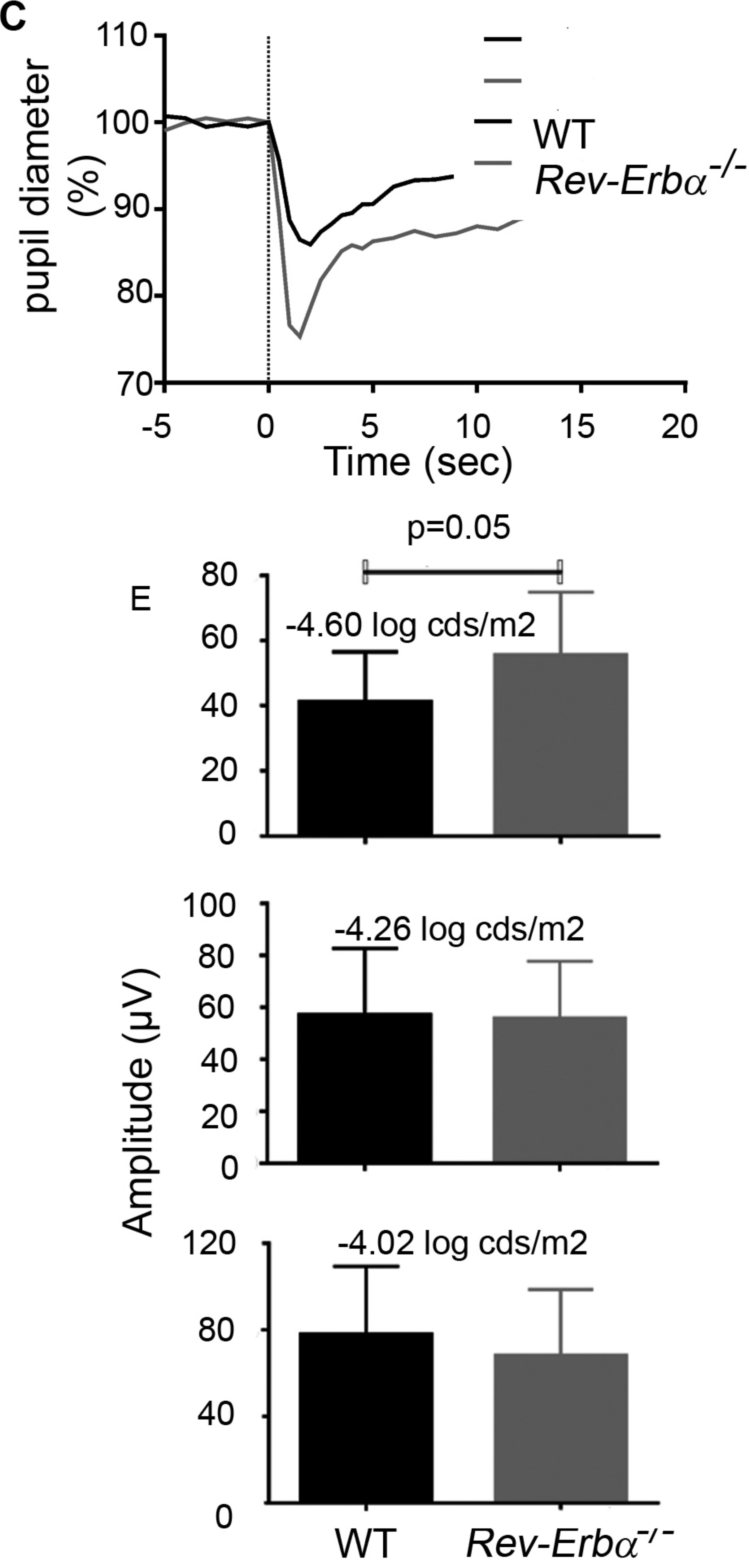
A

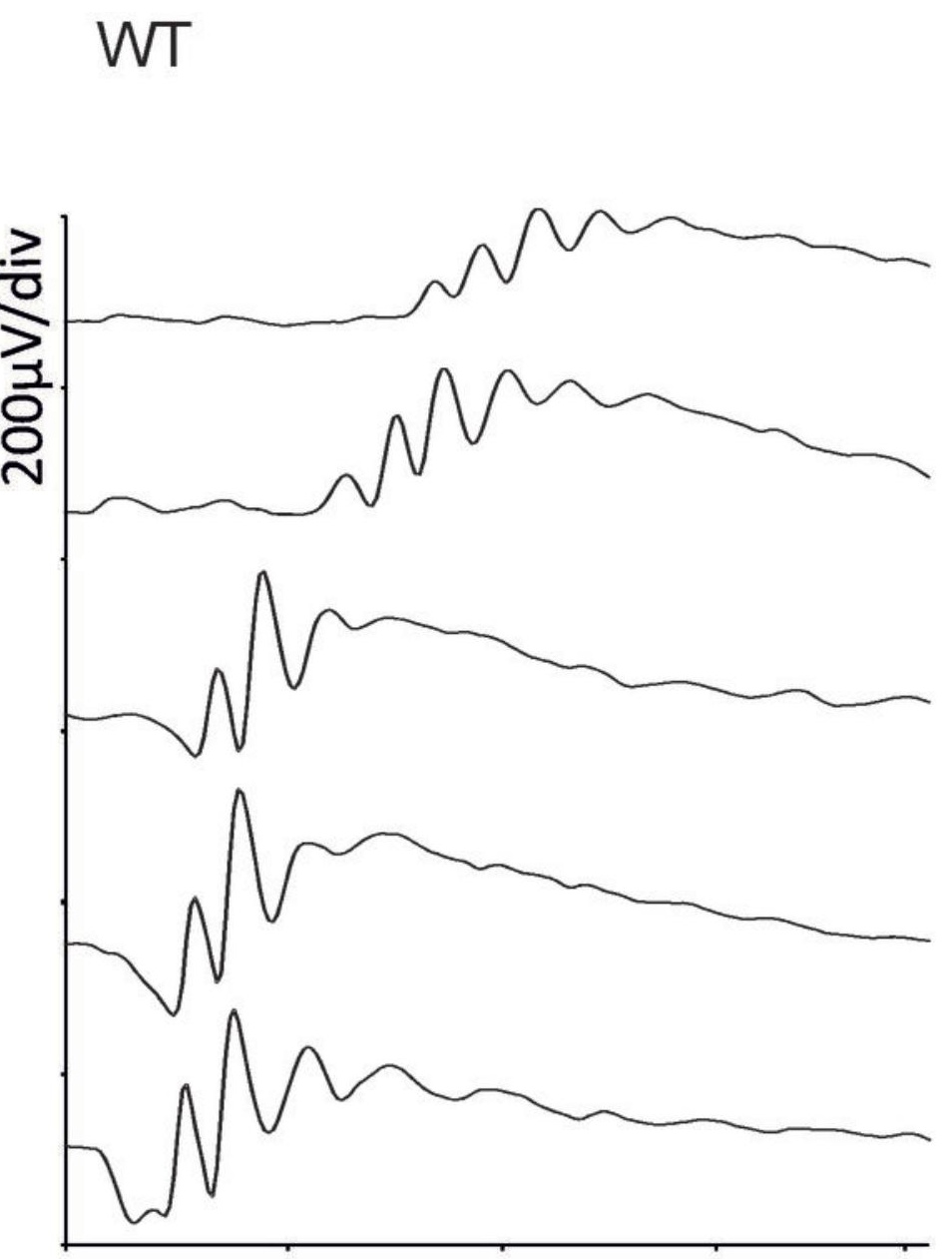

$50 \mathrm{msec} / \mathrm{div}$.

B

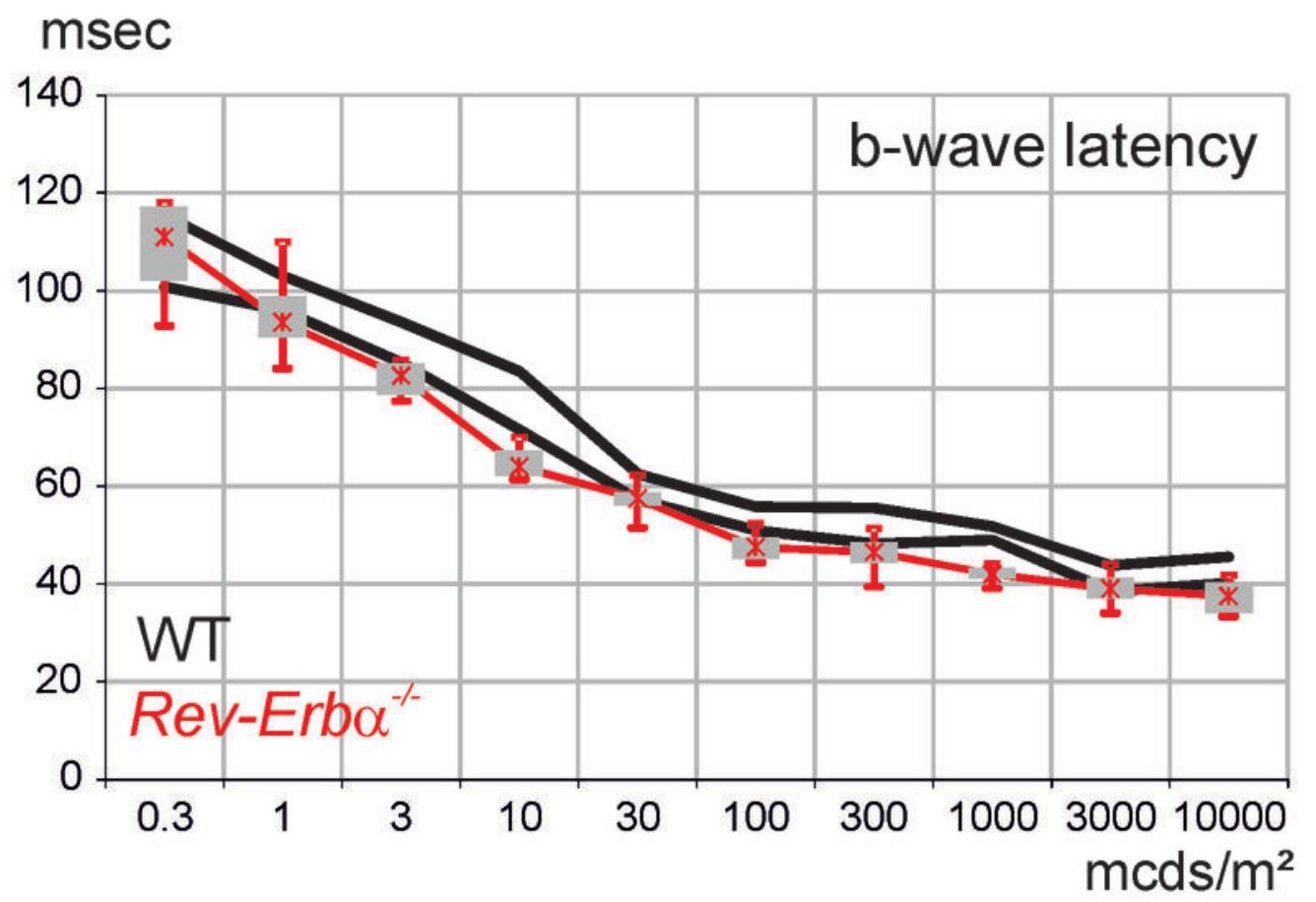

E

$\mu \mathrm{V}$

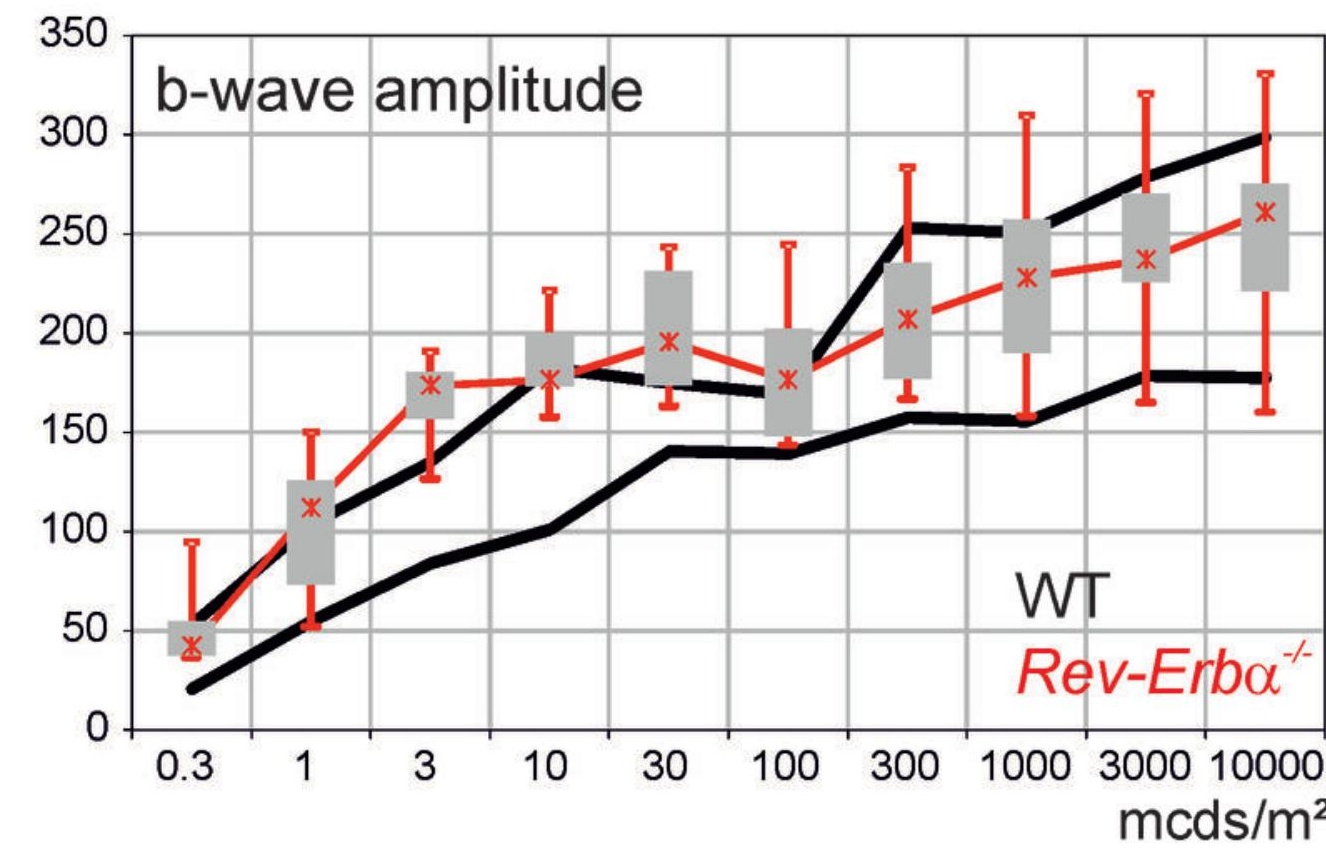

F

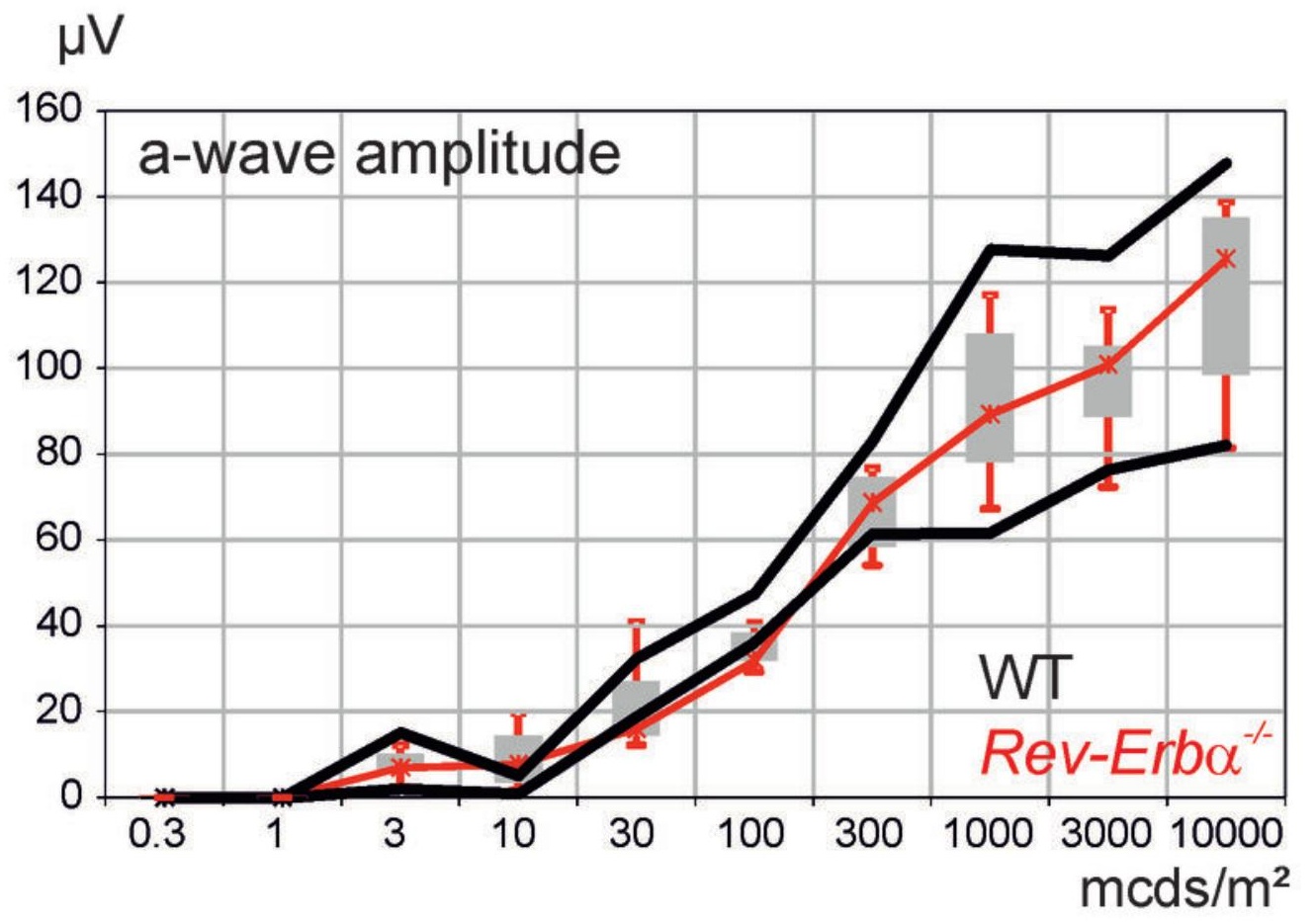

WT

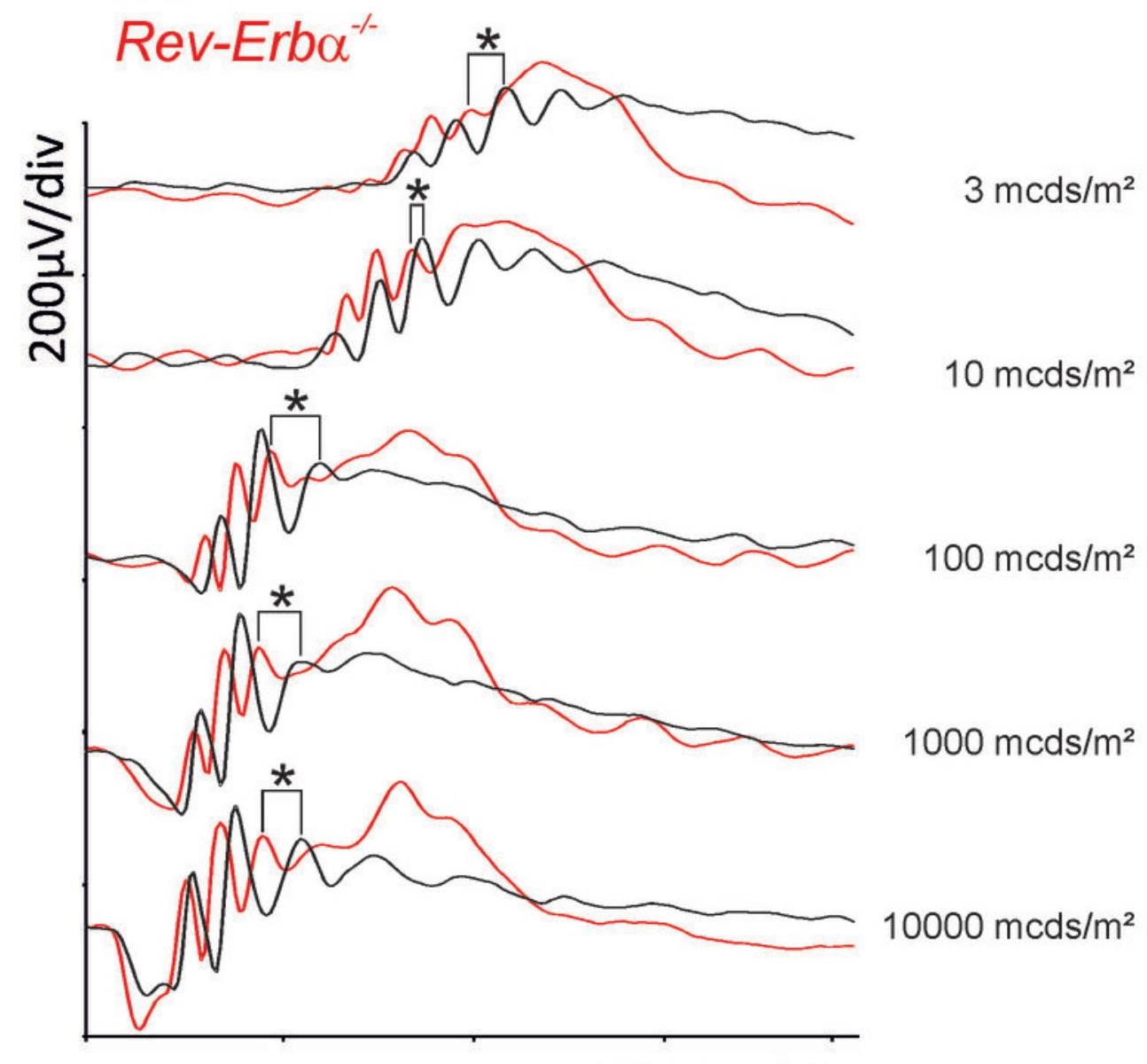

$50 \mathrm{msec} / \mathrm{div}$.

D

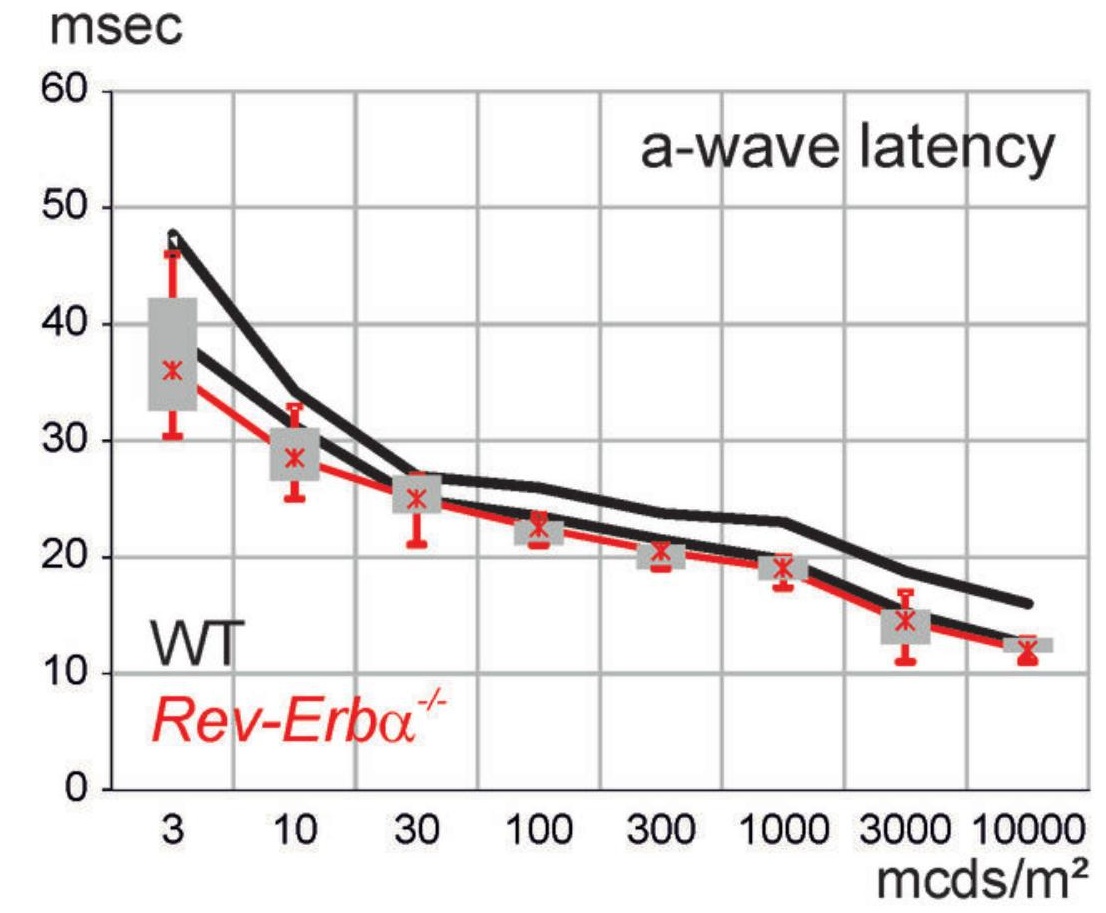

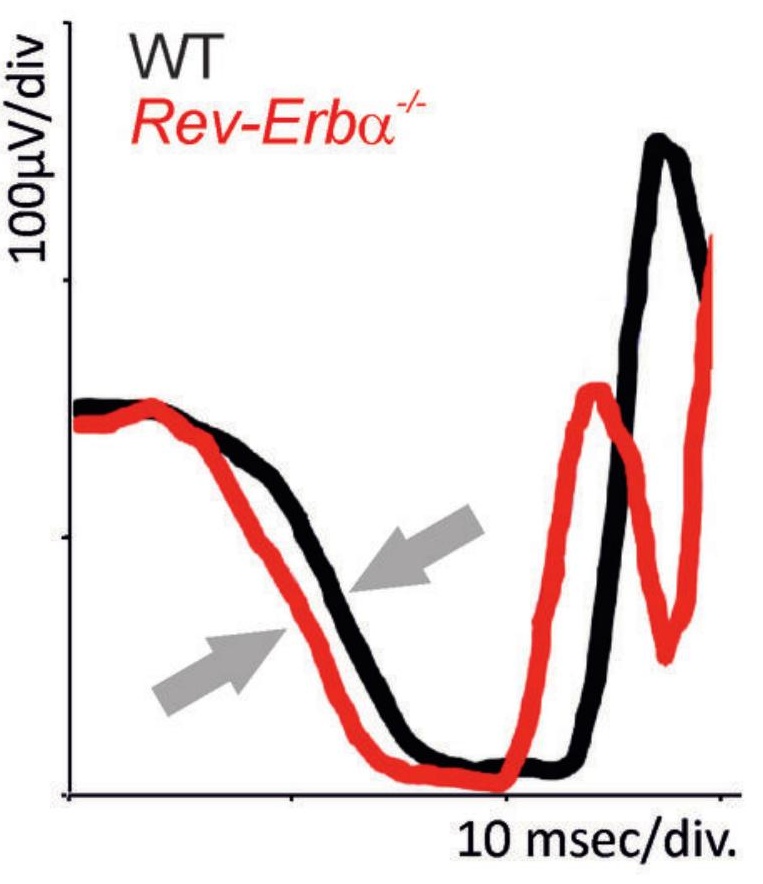

G

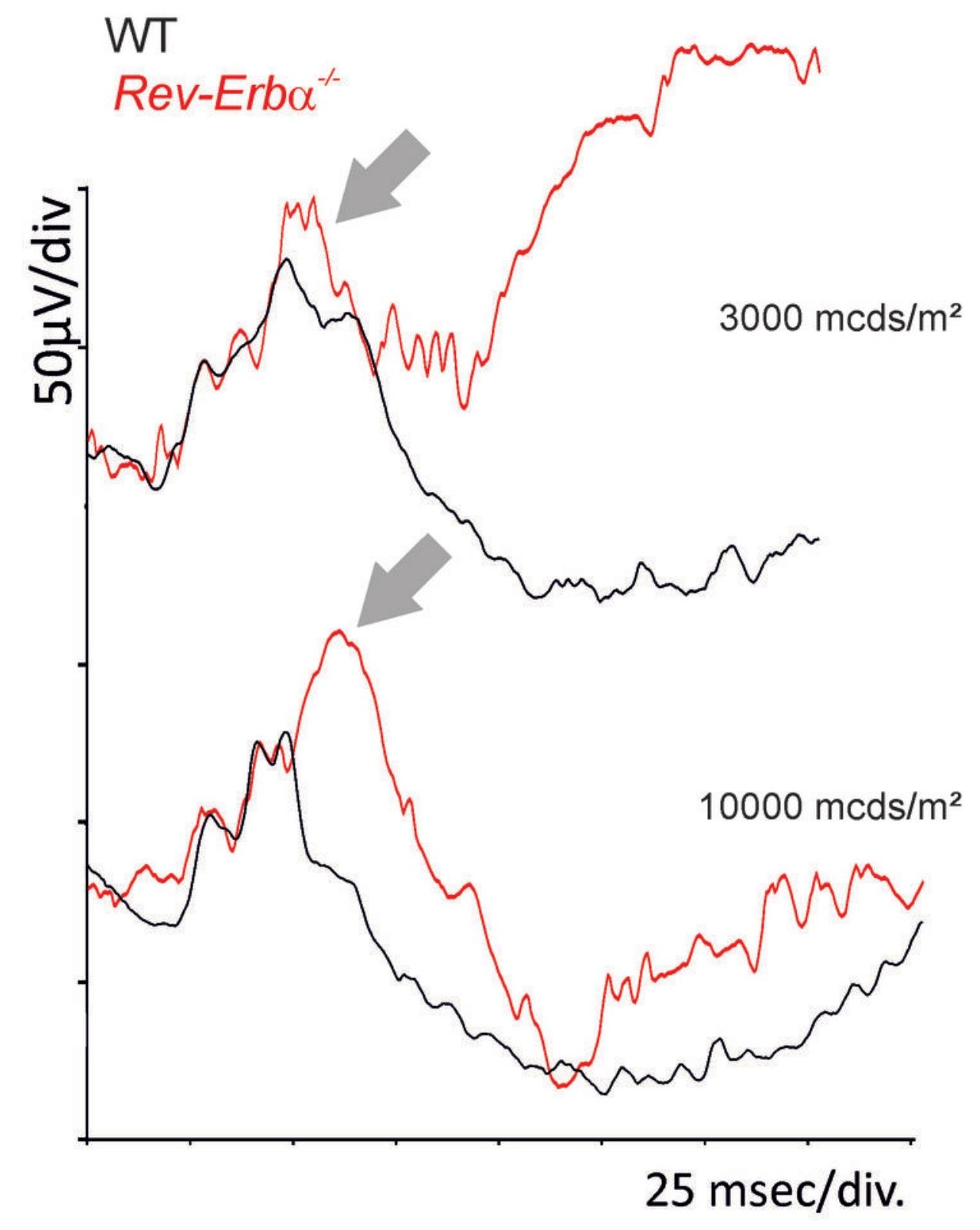


A
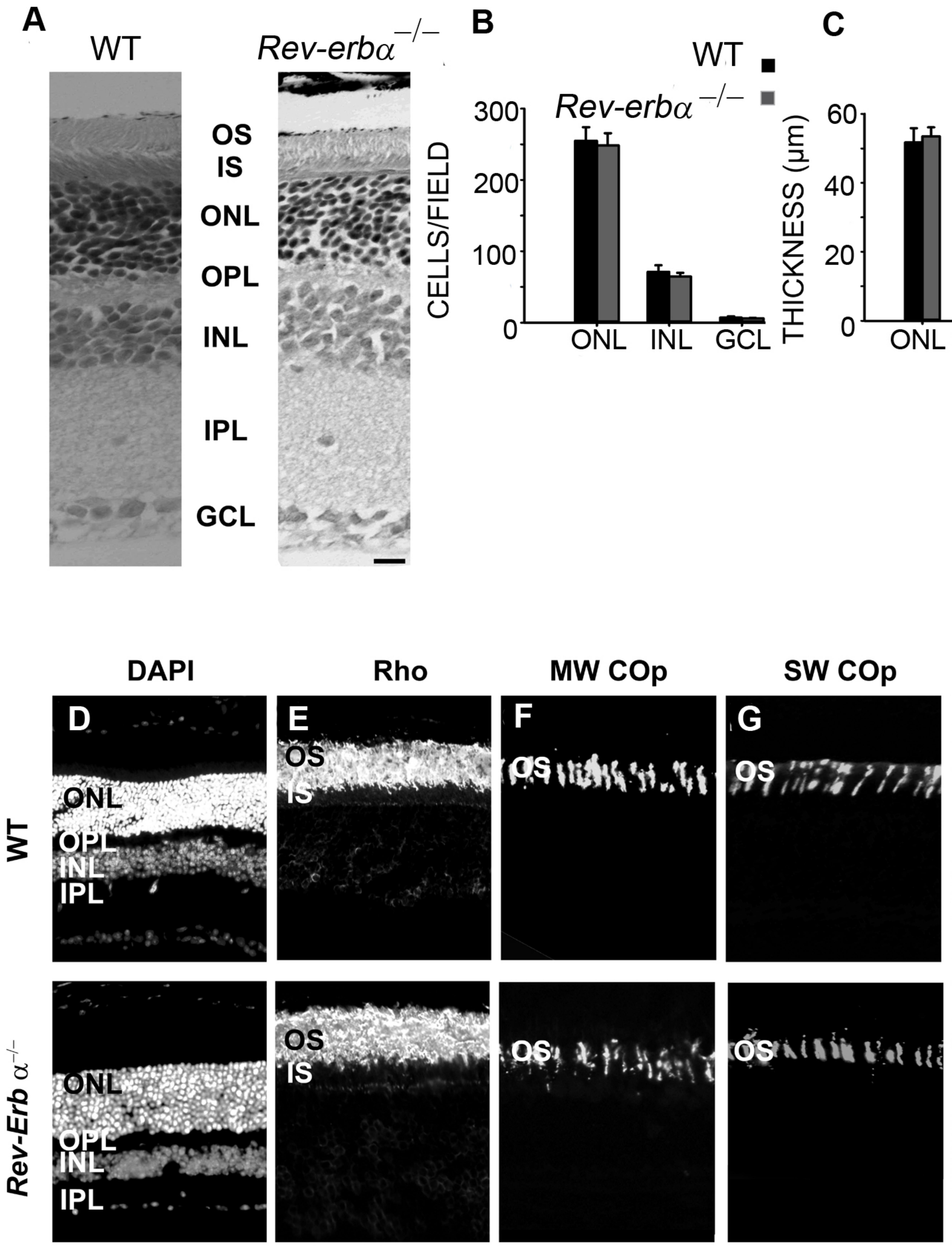

estrintio biof at

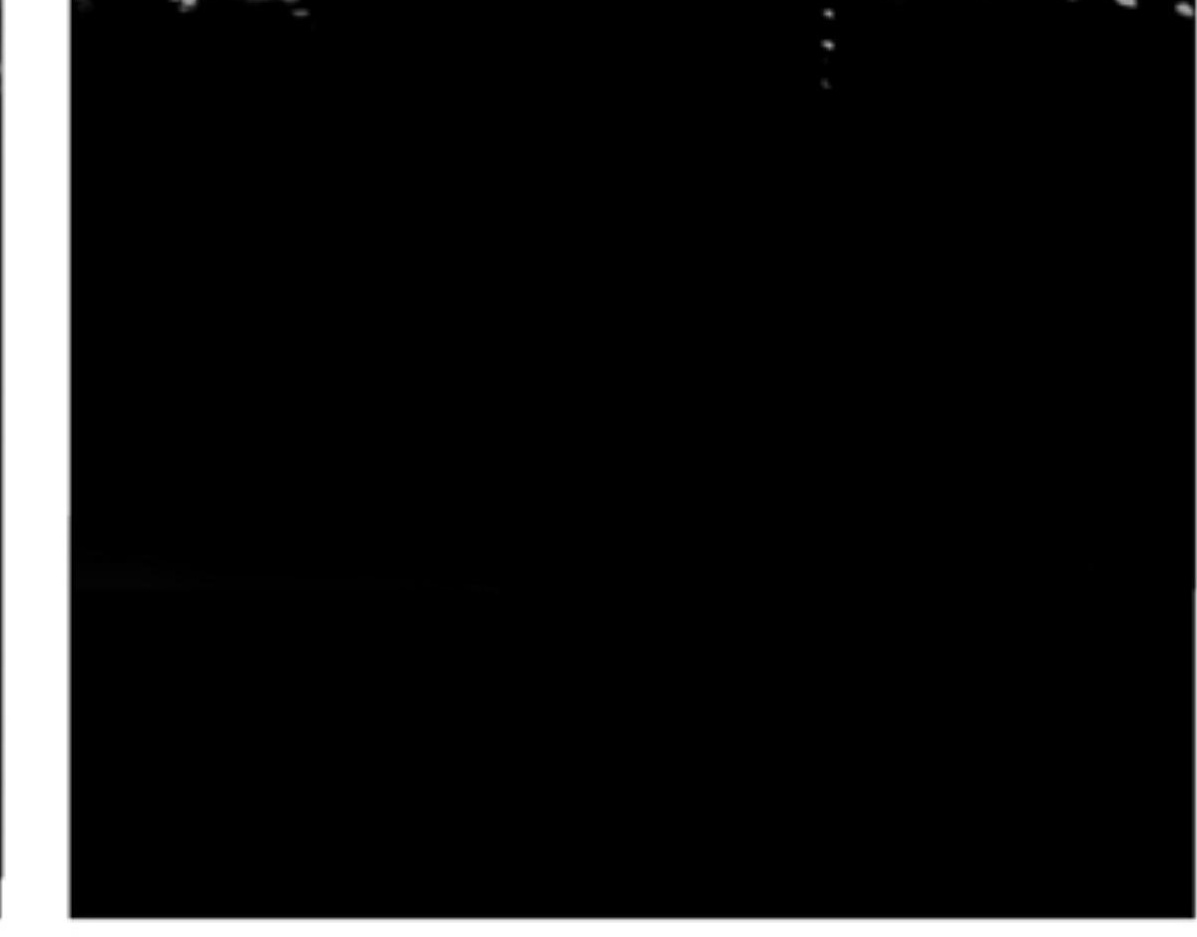

INL
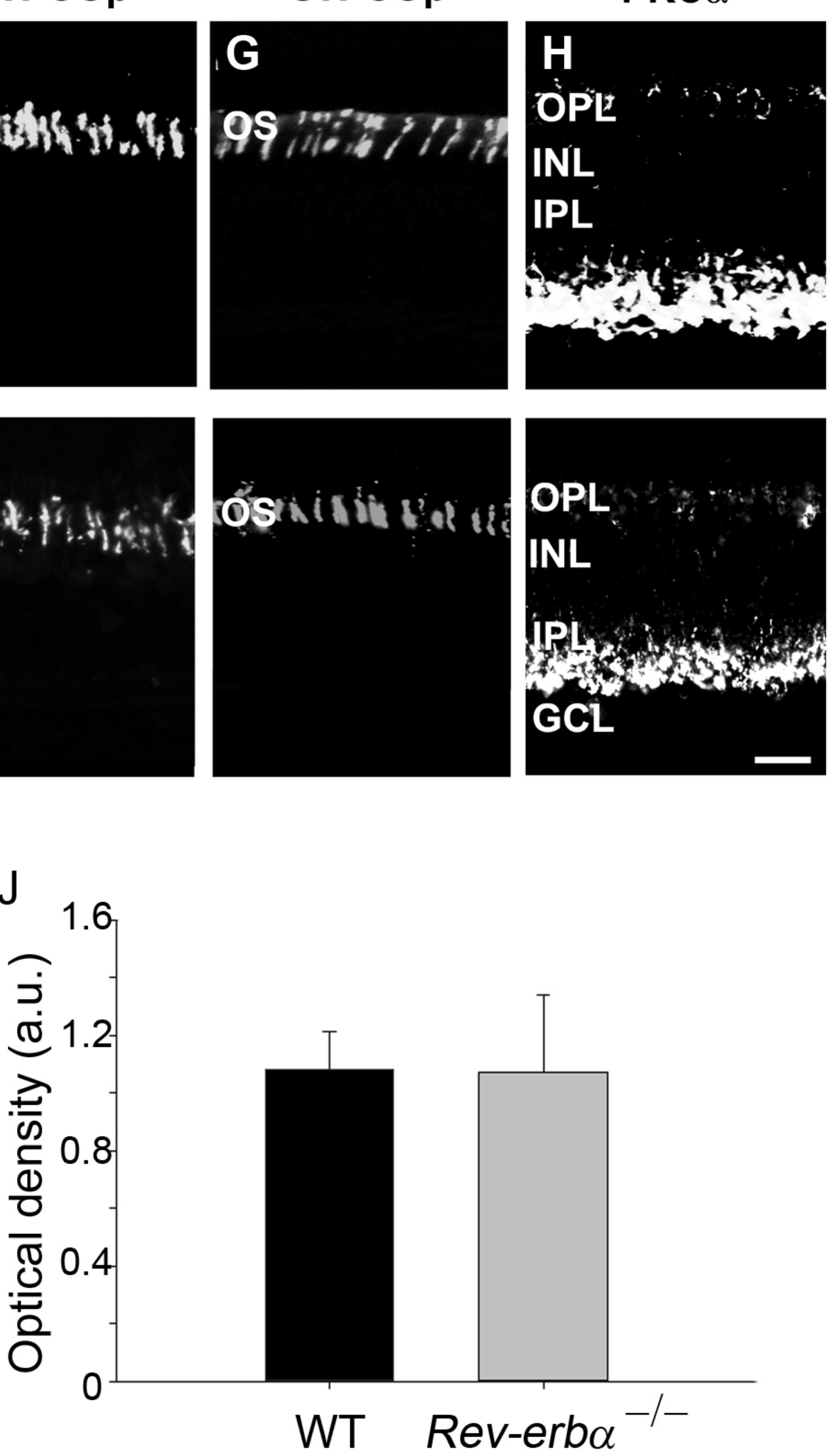


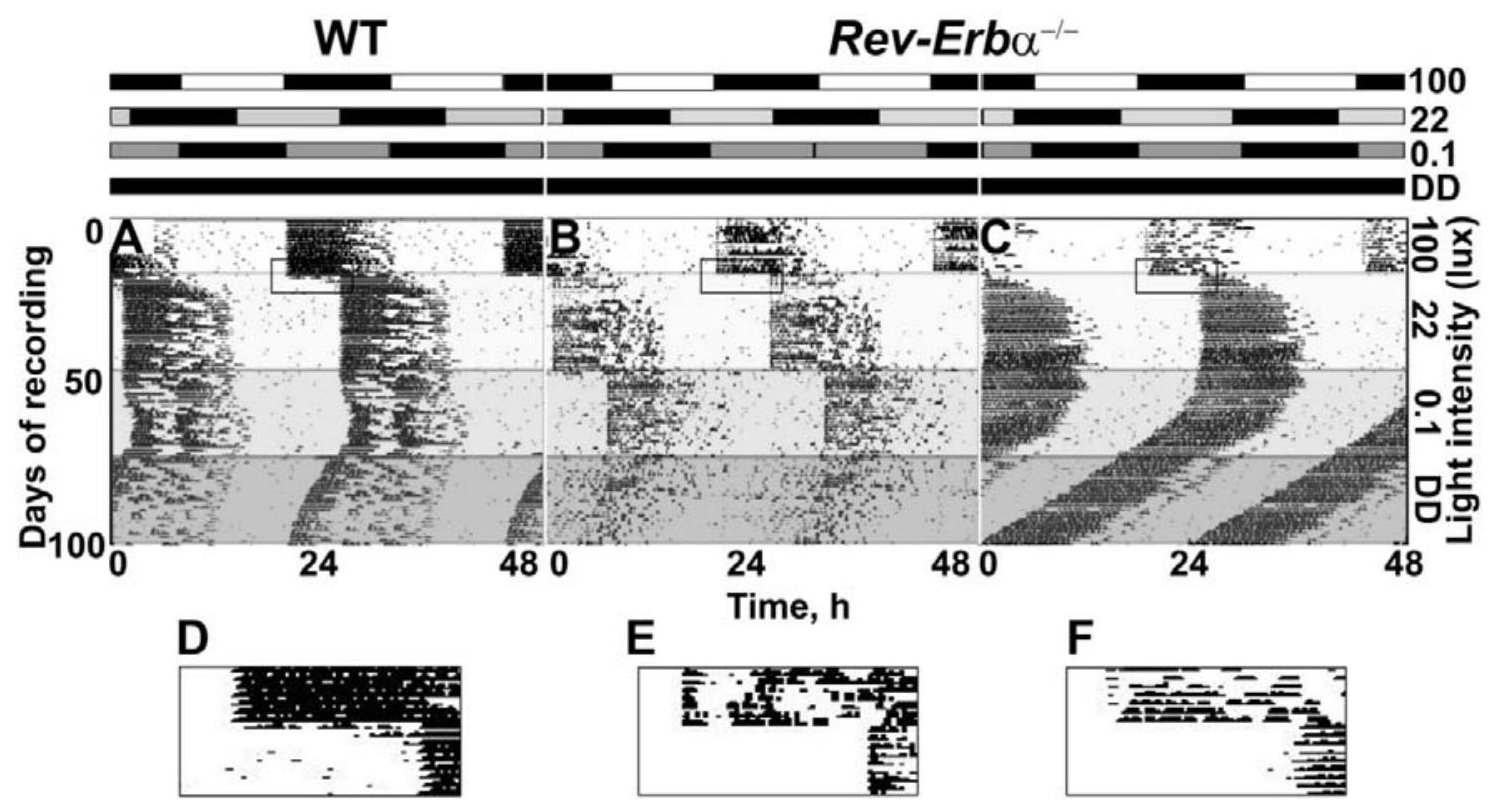

Figure S1

Figure S1. Rev-Erbo $\alpha^{-/}$mice show altered responses to combined jetlag and light intensity reduction compared to WT mice. A) one representative WT double plotted actogram; B, C) Two representative Rev-Erb $\alpha^{-/}$actograms. The successive LD cycles are represented by overlays of increasing grayness, duration of each LD cycle is given on the left and light intensities are indicated on the right (100, 22, 0.1 lux or DD for constant dark). Numbers below actograms signify time. In the initial phase, both WT and Rev-Erb $\alpha^{-/-}$mice were synchronized to the 100 lux LD cycle. After $18 \mathrm{~d}$, animals were subjected to a $6 \mathrm{~h}$ phase delay coupled with a reduction in light intensity to 22 lux; whereas WT mice required $\sim 4$ days to re-adjust their onset of activity in the new cycle (shown in $D$, enlargement of the rectangle in $A$ ), in all cases $R e v-E r b \alpha^{-1-}$ mice very rapidly re-aligned their onset of activity with the start of the new night phase (rectangles in $B$ and $C$ shown enlarged in $E$ and $F$ respectively). When similar tests were conducted with a $6 \mathrm{~h}$ phase delay combined with light reduction from 22 to 0.1 lux, all WT mice were unable to re-entrain to new times, whereas Rev$E r b \alpha^{-/}$mice showed two different behaviors: one group of animals (4 of 10) (B) continued to react to low light levels by adjusting onset of activity with the new LD cycle, and the other group (C) (6 of 10) displayed free-run behavior. In DD condition, both genotypes displayed free run patterns. 
A

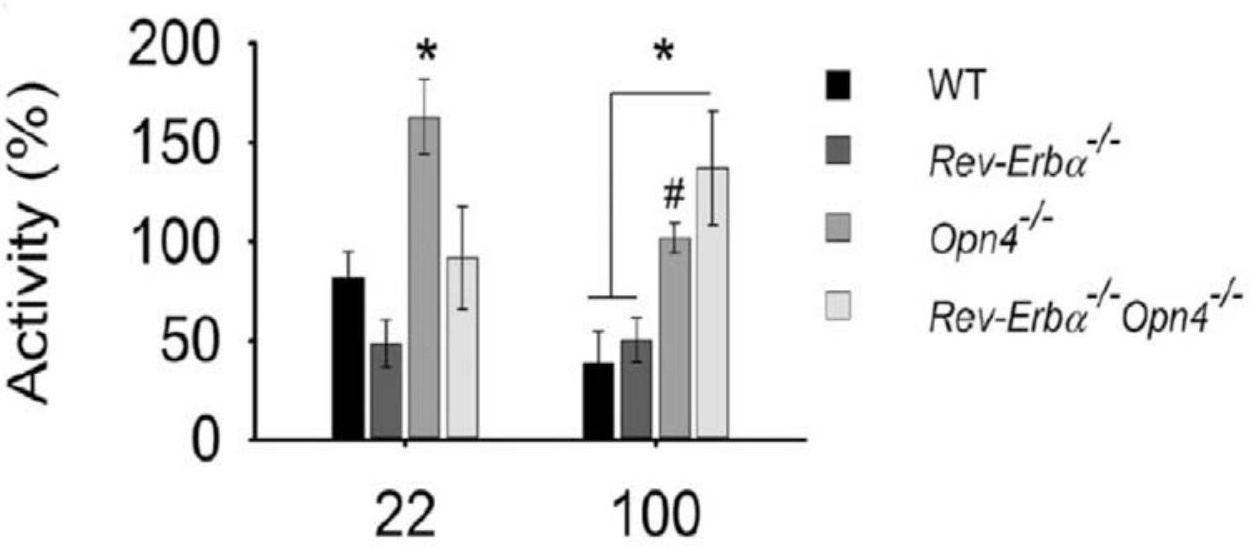

B

\section{Intensity (lux)}
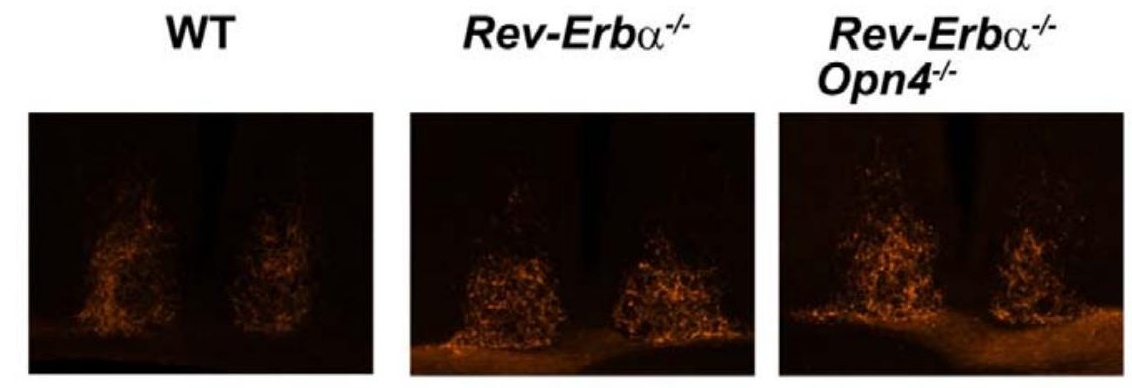

Opn $4^{-1}$

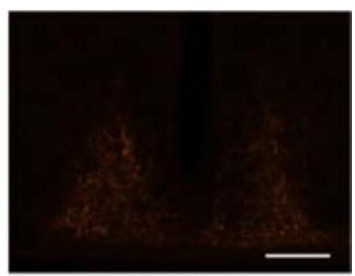

Figure S2

S. 2: Masking responses to higher light intensities and SCN projections in mice lacking Rev-Erb $\alpha$ and/or Opn4.

A) Exposure to a 22 and 100 lux light pulse during the night phase of a 12L/12D

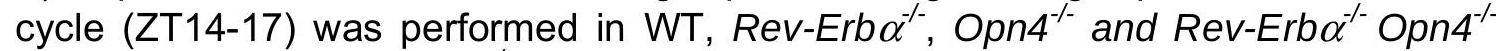
mice. Whereas the Opn $4^{-/}$mice did not show masking at either light intensity (ANOVA 22 lux, $F_{3,17}=7.81, P=0.003 ; 100$ lux, $F_{3,17}=7.2, P=0.004$ ), double null Rev-Erb $\alpha^{-/-}$Opn $4^{-/-}$mice did not display negative masking behaviour at the 100 lux light intensity. *significantly different from the other genotypes and \# different to the control WT (post-hoc test, $P<0.05$ ). B) CTB tracing of ipRGC terminals within the SCN showed intense staining in all genotypes. Representative images, $n=2-3$ for each strain; $P=0.962$. 


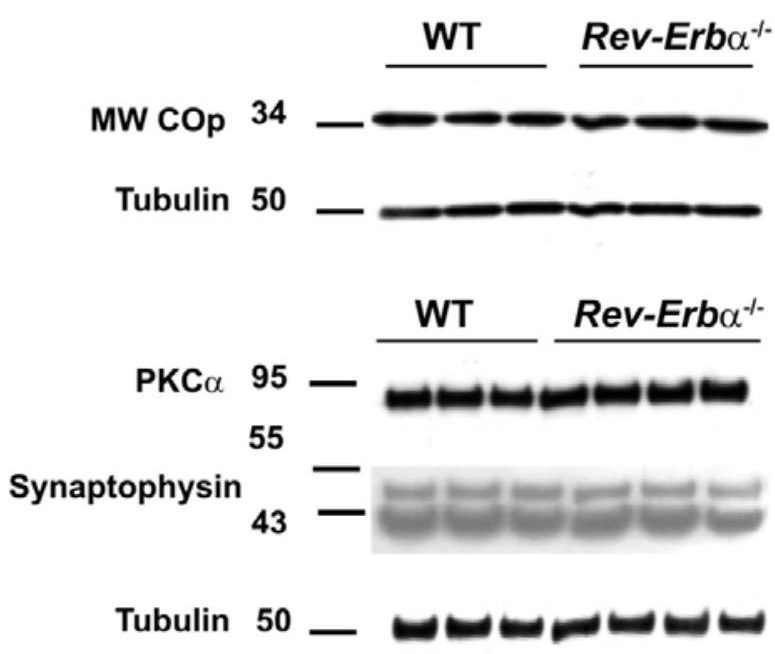

B

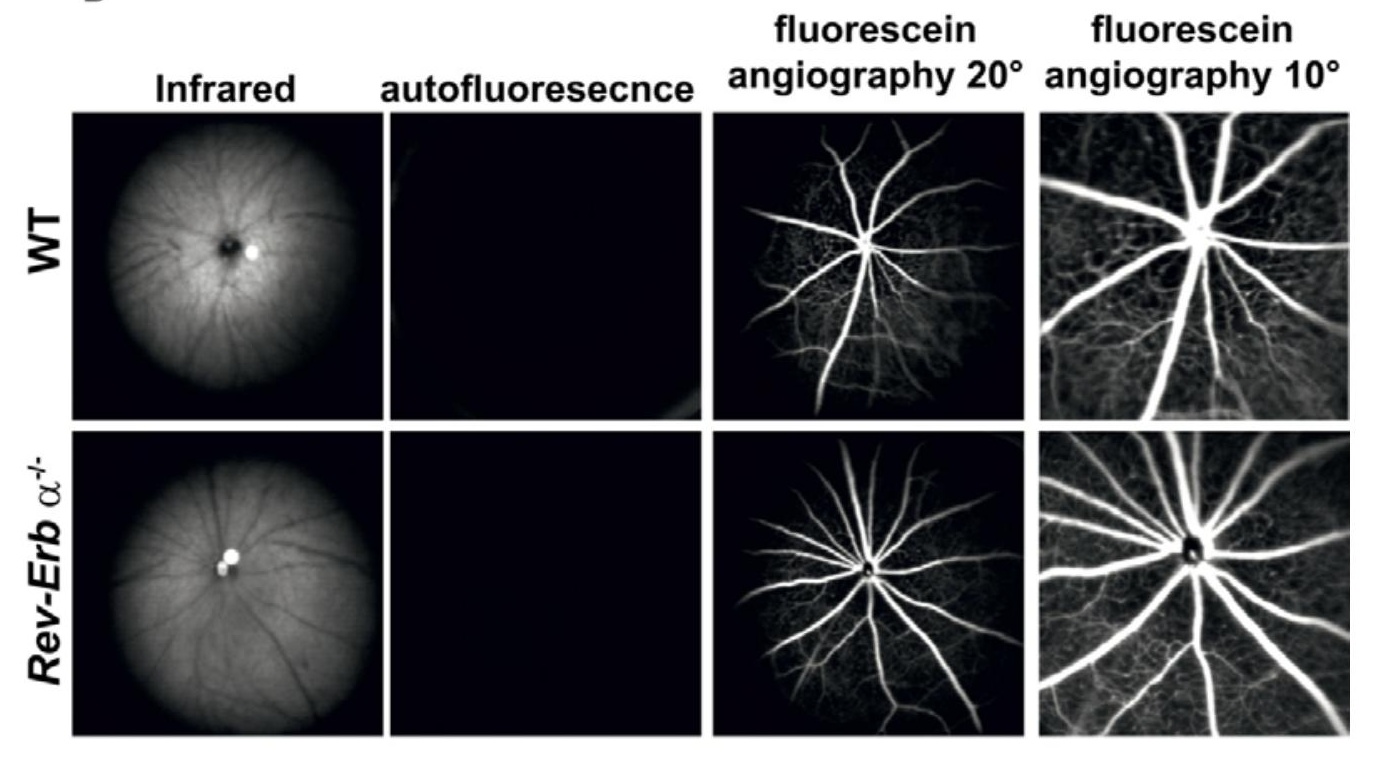

Figure S3

S. 3: No structural differences could be seen between WT and Rev-Erb $\alpha^{-/-}$retinas. A) Quantitative levels of retinal proteins are similar between WT and Rev-Erbo ${ }^{-/-}$mice. Western blotting of candidate photoreceptor and retinal neuronal proteins showed similar expression levels in both genotypes. Top: MW COp; middle : PKCa; bottom synaptophysin ; $\alpha$-Tubulin was used as a representative loading control. In each immunoblot, samples from 3 independent WT retinas are shown on the left, and from 3-4 independent Rev-Erb $\alpha^{-/-}$retinas on the right; MW markers are given in the left margin. B) The retinal structures of the mice still under anesthesia were visualized via imaging with a Heidelberg Retina Angiograph (HRA I, Heidelberg Engineering, Germany) and a confocal scanning laser ophthalmoscope (SLO), according to previously described procedures [40]. The HRA features two argon wavelengths (488 $\mathrm{nm}$ and $514 \mathrm{~nm})$ in the short wavelength range and two infrared diode lasers $(795 \mathrm{~nm}$ and $830 \mathrm{~nm}$ ) in the long wavelength range. Laser wavelengths used for fundus visualization were: $514 \mathrm{~nm}$ (red-free channel), and $488 \mathrm{~nm}$ for autofluorescent images, with a barrier filter at $500 \mathrm{~nm}$. Two device settings for the field of view were used: for fundus overview, the focus was adjusted to $20^{\circ}$, and for magnification and detailed view, the focus was set at $10^{\circ}$. 